\title{
TRUST IN LENDING
}

\author{
Richard T. Thakor \\ Robert C. Merton \\ Working Paper 24778 \\ http://www.nber.org/papers/w24778
}

\author{
NATIONAL BUREAU OF ECONOMIC RESEARCH \\ 1050 Massachusetts Avenue \\ Cambridge, MA 02138 \\ June 2018
}

We thank Barney Hartman-Glaser (discussant) and participants at the 2018 Financial Intermediation Research Society Conference, 2018 North American Summer Meeting of the Econometric Society, and Minnesota Junior Finance Conference for helpful comments. We also thank Xuelin Li for research assistance. We alone are responsible for remaining errors, if any. The views expressed herein are those of the authors and do not necessarily reflect the views of the National Bureau of Economic Research.

At least one co-author has disclosed a financial relationship of potential relevance for this research. Further information is available online at http://www.nber.org/papers/w24778.ack

NBER working papers are circulated for discussion and comment purposes. They have not been peer-reviewed or been subject to the review by the NBER Board of Directors that accompanies official NBER publications.

(C) 2018 by Richard T. Thakor and Robert C. Merton. All rights reserved. Short sections of text, not to exceed two paragraphs, may be quoted without explicit permission provided that full credit, including $\left({ }^{\circ}\right.$ notice, is given to the source. 
Trust in Lending

Richard T. Thakor and Robert C. Merton

NBER Working Paper No. 24778

June 2018

JEL No. E44,E51,E52,G21,G23,G28,H12,H81

\begin{abstract}
$\underline{\text { ABSTRACT }}$
We develop a theory of trust in lending, distinguishing between trust and reputation, and use it to analyze the competitive interactions between banks and non-bank lenders (fintech firms). Trust enables lenders to have assured access to financing, whereas a loss of investor trust makes this access conditional on market conditions and lender reputation. Banks endogenously have stronger incentives to maintain trust. When borrower defaults erode trust in lenders, banks are able to survive the erosion of trust when fintech lenders do not. Trust is also asymmetric in nature-it is more difficult to gain it than to lose it.
\end{abstract}

Richard T. Thakor

University of Minnesota

321 19th Avenue South, 3-255

Minneapolis, MN 5545

rthakor@umn.edu

Robert C. Merton

MIT Sloan School of Management

100 Main Street, E62-634

Cambridge, MA 02142

and NBER

rmerton@mit.edu 


\section{Introduction}

This paper examines the role of trust in affecting the cost of lending and credit market competition between banks and non-banks. Trust in financial products and institutions is often essential for financial markets to function efficiently. Since the very origins of banking, trust has played a foundational role in banks, with "my word is my bond" defining the very essence of banks with regard to their safekeeping and depository functions. This notion of trust in financial institutions also has deep implications for the credit that lenders provide, since intermediaries use the funds they raise from depositors and investors to make loans. For example, if a bank uses the money it raises via deposits to knowingly make a bad loan, then it endangers the trust that depositors place in the bank and hence future funding. In line with this, the concept of trust has emerged in policy discussions regarding the potential impact of non-intermediated credit on banks and the credit market, with particular focus on financial technology (fintech) lenders such as peer-to-peer (P2P) lending platforms (see He et al. (2017)). Even with fintech lending, practitioners and market participants understand the role of trust in enabling fintech firms to compete with banks. ${ }^{1}$

Trust in lending is therefore central to financial intermediation - it affects the ability of banks and other intermediaries to sustain their funding models. But analyzing trust can also generate a perspective on the future evolution of the credit market in the face of the growth of non-intermediated credit such as P2P and other fintech lending. Ever since the 2007-2009 financial crisis, P2P lending platforms and other types of lending by fintech companies have been growing at a rapid clip. ${ }^{2}$ Although still small compared to bank lending, this lending has come at a time when bank lending capacity seems to not be growing (see Fenwick, McCahery, and Vermeulen (2017) and Demyanyk, Loutskina, and Kolliner (2017)). This

\footnotetext{
${ }^{1}$ For example, Rhydian Lewis, co-founder and chief executive of RateSetter, says "Banks can currently access money more cheaply than marketplace lenders and, in order to be truly competitive, this gap must reduce. The route to this for lending platforms is to build trust and acceptance, which comes with a strong track record" (see Green (2016)).

${ }^{2}$ While it initially started as non-intermediated platform-assisted credit transactions between peers, the investors in these platforms are now mainly institutional investors; during the first quarter of 2016, only $15 \%$ of Lending Club's loans came from individuals investing on their own (see Salisbury (2016)).
} 
has been observed not only in the U.S. but also in Europe, causing many to debate whether fintech companies will eventually replace banks in performing lending and other functions (e.g. Sorkin (2016)). While we have not yet observed any major crises or scandals in fintech lending, there are many ways in which they can create suspicion of being untrustworthy. ${ }^{3}$ Our analysis suggests that the growth of fintech firms may be halted if there is an event that erodes trust; this would cause funding to dry up and their borrowers to return to banks. We therefore posit that understanding the role of trust in lending is central to understanding the future evolution of the credit market, especially in terms of the relative provision of intermediated and non-intermediated credit.

These developments raise a number of important questions: What is the effect of trust on the access to and cost of financing for lenders? How is trust related to and different from lender reputation? What incentives do lenders have to maintain trust and what can erode it? How do these incentives differ across banks and fintech lenders?

We develop a theoretical model in order to address these questions. As a starting point, we note that from a functional perspective (e.g. Merton (1990, 1993, 1995) and Merton and Bodie (1995, 2005)), the lending functions of banks and fintech firms are similar-both provide debt financing to clients. However, these lenders have different institutional features. We therefore take an institutional perspective in order to examine the differences between banks and fintech firms in terms of their ability to endogenously sustain trust.

In taking this institutional perspective, we focus on one key difference between banks and fintech lenders, which is that banks raise significant financing through deposits (and thus are leveraged lenders), whereas fintech lenders like P2P platforms are all-equity financed (see Philippon $(2015,2016)) .{ }^{4}$ We draw upon the earlier work of Merton $(1993,1995,1997)$ and

\footnotetext{
${ }^{3}$ For example, Lending Club sold a major portfolio of $\$ 22$ million to a large investor and subsequently discovered the loans were neither what Lending Club had advertised nor what the investors had asked for. Lending Club bought back the loans and launched an investigation that led to the firing of three senior executives. See Wallace (2016).

${ }^{4}$ Not all fintech lenders are all-equity financed, but the key is they are non-banks with no access to deposits. Thus, the crucial distinction between banks and fintech that our analysis relies on is that banks have access to lower-cost funding via deposits, but fintech lenders lack this access.
} 
Merton and Thakor (forthcoming) in which the bank's depositors are viewed as customers who are provided valuable liquidity services and are insulated from the bank's credit risk through a combination of deposit insurance and the bank's actions, whereas fintech lenders have no such "customer relationship" with their financiers. This gives banks a potential funding cost advantage over fintech lenders as well as an endogenous economic motivation to act in a more trustworthy manner in investing their funds. While in practice there are other differences too, such as fintech lenders having a technological and regulatory cost advantage over banks, these differences do not appear in our main analysis. ${ }^{5}$ Thus, in our base model, one could broadly interpret a fintech firm as any non-depository lender. However, we discuss the implications of additional features unique to fintech within the context of our model. For example, our analysis implies that if banks face higher regulatory costs than fintech lenders and these costs are higher for riskier borrowers, the market will segment with fintech lenders taking away the riskiest borrowers. ${ }^{6}$ A technological cost advantage for fintech firms allows them to further peel away borrowers from banks.

In order to model trust, we follow Fehr (2009), who argues that a behavioral definition of trust is the most appropriate and that the development or erosion of trust is often more than just inferring a priori unknown types from observations. ${ }^{7}$ Indeed, trust often has a 0-1 property - you either trust someone or you do not. ${ }^{8}$ Unlike Fehr (2009), however, we model trust using Ortoleva's (2012) model of (partly) non-Bayesian belief revision in which agents

\footnotetext{
${ }^{5}$ For example, as Morrison and White (2005) point out, regulatory screening of banks improves the quality of banks given operating licenses. In our context, this implies that bank lending may be more prudent on average than that of less-regulated non-banks. We show that this can arise endogenously even absent regulatory intervention. Moreover, in our analysis, all of the bank's non-equity funding comes from insured deposits. If regulatory screening of banks had an influence at the margin on bank asset quality, even uninsured deposit funding would be cheaper for banks than for non-banks.

${ }^{6}$ See Jagtiani and Lemieux (2017), Demyanyk, Loutskina, and Kolliner (2017), and de Roure, Pelizzon, and Thakor (2017) for evidence.

${ }^{7}$ Fehr (2009, p. 238) notes: "An individual...trusts if she voluntarily places resources at the disposal of another party (the trustee) without any legal commitment from the latter. In addition, the act of trust is associated with an expectation that the act will pay off in terms of the investor's goals. In particular, if the trustee is trustworthy the investor is better off than if trust were not placed, whereas if the trustee is not trustworthy the investor is worse off than if trust were not placed."

${ }^{8}$ Fehr (2009) notes that this can be modeled via betrayal aversion, and points out "...people are more willing to take risk when facing a given probability of bad luck than to trust when facing an identical probability of being cheated."
} 
face uncertainty both about the correct model of the world ("is the lender trustworthy or self-interested?") as well as about the lender's "type" within a given model (if self-interested, is the lender still worth financing?). Within-model uncertainty is a reputational effect and is captured by the usual prior beliefs, whereas uncertainty about the true model is captured by a prior over priors. This then leads to a belief revision process that is Bayesian in some states and non-Bayesian in others, providing an ideal framework for analyzing lender reputation and trust simultaneously. In this framework, a lender is trusted if agents adopt a model of the world that the lender will never make a bad loan; this leads to an analysis in which market conditions and lender performance do not affect the lender's cost of funding. ${ }^{9}$ But in the face of sufficiently strong ex post evidence that this model is incorrect, trust is lost (via nonBayesian belief updating) - lenders are viewed as self-interested, and market conditions and lender performance (reputation) influence the cost and availability of financing to lenders, with post-model-shift beliefs revised in a Bayesian manner. ${ }^{10}$

We motivate our modeling of trust by noting a remarkable feature of the 2007-2009 crisis, namely the alacrity with which the effect of stress was manifested. Gorton and Metrick (2012) document that the average haircut on bilateral repo transactions (excluding U.S. Treasuries) rose from zero in early 2007 to almost $50 \%$ at the peak of the crisis in late 2008 , with several classes of assets having $100 \%$ haircuts, i.e., they were excluded entirely from being used as collateral. Similarly, Iyer, Lopez, Peydro, and Schoar (2013) documented an unexpected and sudden freeze of the European interbank market in August 2007. These are examples

\footnotetext{
${ }^{9}$ In fact, the trust perspective also helps to shed light on a puzzling stylized fact. During the 2007-2009 crisis, although haircuts on bilateral repos rose sharply, haircuts on tri-party repos remained roughly constant (see Copeland, Martin, and Walker (2011), and Sanches (2014)). One possible reason for this is that there are two banks - Bank of New York Mellon and JP Morgan - that act as third-party agents for U.S. tri-party repo transactions, and these institutions maintained the trust of investors during the crisis. Since tri-party agents are involved in collateral selection, payment and settlement as well as essentially financing collateral sellers (borrowers) for most of the day during intraday unwinding and resetting of contracts, investor trust in these tri-party agents is important. Such agents are absent in bilateral repos.

${ }^{10}$ Our modeling of within-model uncertainty is somewhat similar to Hartman-Glaser (2017), where there is asymmetric information about issuer preferences for honestly revealing quality. In that model, asset retention by an issuer selling the asset acts as a signal of asset quality, and reputation induces pooling, in contrast to the static case in which the equilibrium is separating. In our model, there is no securization or loan retention decision, and uncertainty about the true model plays a central role.
} 
of discontinuities in pricing that suggest non-Bayesian belief revision by agents about the economic environment - agents believing in a particular model of the economic environment and then, faced with unexpected news, switching to a different model. We believe that such behavior is plausibly understood in a trust framework - economic agents trust that the financial products and institutions they are dealing with have certain attributes, but then that trust is lost when unexpectedly bad news arrives that is incompatible with the initial trust. This can induce a sharp and discontinuous change in prices and trading volume.

This modeling of trust is intended to capture three features. One is that trust reduces an investor's perception of the riskiness of a given investment (as in Gennaioli, Shleifer, and Vishny (2015)), making the pricing of credit seem disassociated from the risk in the environment. Thus, during periods in which lenders are trusted, risk will-from an ex post perspective - appear to be underestimated. For example, Coval, Jurek, and Stafford (2009) document that investors underestimated the probability of mortgage defaults in pricing mortgage-backed securities. ${ }^{11}$ Second, trust may be lost with a minor perturbation of observed outcomes, but when it is lost it can precipitate a crisis that involves a drying up of funding to lenders, consistent wtih sharp discontinuities in prices and trading. Third, a crisis generated by the loss of trust will have the feature that the risks being penalized during the crises were not even contemplated by investors when there was trust. ${ }^{12}$ Lack of contemplation of positive probability events followed by episodes of funding drying up entirely for some institutions when a crisis occurs are not phenomena that can be explained using reputational/career concerns models with Bayesian updating. ${ }^{13}$ The use of model un-

\footnotetext{
${ }^{11} \mathrm{~A}$ reason for trust being placed in these types of lenders and financial technologies in the first place is likely due to a combination of the technologies being opaque and yet working well to begin with. Indeed, if such technologies were transparent, then there may be no need for trust for them to be adopted. We provide a discussion of this point later in the paper.

${ }^{12}$ In the context of the 2007-2009 crisis, evidence presented by Foote, Gerardi, and Willen (2012) indicates that investors did not even contemplate the magnitude of the home price declines that actually occurred.

${ }^{13}$ Discontinuities may also arise in moral-hazard-based reputation models with known types in which the threat of future punishment deters bad behavior and generates trigger strategy equilibria. For example, Winton and Yerramilli (2015) create a model of loan securitization by a bank, in which the moral hazard is that the bank may not monitor the borrower. Reputation acts as a sanctioning mechanism that operates purely through the threat of future punishment imposed on the bank for poor loan performance. In equilibrium, both the punishment threat and loan retention by the bank combine to provide monitoring incentives.
} 
certainty in Ortoleva's (2012) non-Bayesian framework allows us to capture all these three features of trust, but in a way that differs from previous approaches.

Our theory produces the following main results. First, when lenders are trusted, they can raise financing at the lowest possible cost regardless of their prior loan default experience and market conditions, so default risk will appear to be underestimated and hence mis-priced. Second, the lender's ability to maintain the trust of its financiers depends on its post-trust default experience and market conditions - trust can be eroded when lenders experience (significant) defaults during an economic boom. We show that when trust is lost, banks may survive the loss of trust and hence continue to operate in circumstances in which fintech lenders are forced to shut down. That is, while trust is important for all lenders, it is essential for fintech lenders to operate. Third, banks have stronger endogenous incentives to maintain trust, so a potential advantage of banks is that they are trusted lenders. Finally, investor trust has an "asymmetry" property - it is easier to lose it than to gain it. Beyond our model, we also discuss how trust may interact with the informational environment, and in what circumstances additional transparency may substitute for trust.

The intuition for the results is as follows. When lenders are trusted, they are able to obtain the cheapest possible funding. But because banks finance with deposits and provide depositors liquidity services, they share in the associated liquidity benefits and are able to raise financing at a lower cost than fintech lenders, all else being equal. The associated higher profitability is available only when the bank remains solvent, which provides the bank a stronger incentive than the fintech lender to make good loans that have a higher solvency probability. When loans repay, trust is maintained and funding costs remain the same since trusted lenders are believed to unconditionally make only good loans. However,

There are some key differences between these models and ours. One is that our model features both private information and moral hazard and the key to both reputation and trust is the intertemporal learning that occurs about the lender's type, with price adjustments predicated on this learning. Thus, we only admit subgame perfect strategies, thereby precluding trigger-strategy punishments that provide ex ante incentives but may not be subgame perfect. Second, we focus on providing a way to distinguish between credit market reputation and trust in a private-information setting (with unknown types) with the feature that in equilibrium, trust insulates lenders against performance-based risk pricing adjustments, whereas reputation does not. 
if loans default, then investors may question their assumed model of the world that lenders are trustworthy. Trust may still be maintained if default occurs in a "bad" macro state in which such default is relatively likely, but trust will be lost if default occurs in a relatively "good" macro state in which it was unlikely to occur with a trusted lender. A loss of trust means that investors' initially-adopted model is discarded, and investors will now believe that lenders are self-interested. This non-Bayesian model switching causes a discontinuous increase in the funding costs of lenders, with funding possibly drying up for fintech lenders. The reason is that if all lenders are self-interested (and hence not to be trusted), banks will have stronger reputational incentives to make good loans. Recognizing this, investors may be willing to finance self-interested banks, but not self-interested fintech lenders, giving banks a greater ability to survive a loss of trust. ${ }^{14}$

In a nutshell, our basic idea is that trust insulates lenders from the adverse reputational consequences of loan defaults, and the degree of insulation depends on market conditions. Whether they are trusted or must rely on reputation, the depository (customer) relationships banks have are a source of rents - unavailable to fintech lenders - that influence banks to make good loans in some states even when they are self-interested. This is what enables banks to survive when trust is lost, a circumstance in which fintech lenders shut down.

The rest of the paper is organized as follows. Section 2 reviews the related literature. Section 3 develops the model. Section 4 provides an analysis of the first best. Section 5 analyzes the second best. Section 6 discusses extensions and additional implications of the analysis. In this section, we discuss the implications of introducing costs of bank regulation and of operating fintech lending platforms, transparency versus opaqueness for lenders, and the viability of financial innovations. Section 7 concludes. All proofs are included in the Appendix.

\footnotetext{
${ }^{14}$ Our analysis does not consider the contagion effects of a loss of trust, a feature that may amplify the effects we model. For example, in a reputation model, Morrison and White (2013) model the regulator's reputation and show that this can give rise to contagion effects, whereby the failure of one bank may indicate regulatory incompetence and induce investors to withdraw funding from other banks.
} 


\section{Related Literature}

Our paper is also related to work on the role of trust in financial markets. Guiso, Sapienza, and Zingales (2008) develop a model in which the individual's trust that he will not be cheated determines whether he will participate in the stock market. Less trusting individuals are less likely to buy stock, and buy less when they do participate. Their calibration of the model indicates that mistrust is sufficiently severe to explain limited participation in the U.S. and differences across countries. Sapienza and Zingales (2011) review this literature. Our work is complementary in the sense that whether institutional lenders have the trust of investors affects whether investors are willing to fund these lenders. ${ }^{15}$ However, there are numerous differences, the key one being our focus on the role of trust in determining the cost and availability of financing to institutional lenders and the resulting nature of the competitive interaction between banks and fintech lenders. Other differences are our modeling of the way trust can be lost and the asymmetric nature of trust.

Another paper in which trust plays a role is Gennaioli, Shelifer, and Vishny (2015a). In that model, trust in investment advisors helps to reduce the risk that risk-averse investors perceive in investing in assets recommended by the advisor. Net of advisors' fees, investors do worse than the market, but they still prefer to pay fees. When investors have biased expectations and chase hot stocks, even trusted advisors pander to their clients' beliefs rather than correcting them. This is quite a different notion of trust from what we model, in at least three respects. First, in our model, all agents are risk neutral, so trust plays no role in reducing risk-aversion-related anxiety. Second, a lender that is truly a trusted lender never violates the trust; it is only self-interested lenders mistaken as trusted lenders that violate trust at times. And finally, our focus is on a very different set of issues, including incentives to maintain trust that differ across lenders and the asymmetric nature of trust in

\footnotetext{
${ }^{15}$ Recently, Gurun, Stoffman, and Yonker (forthcoming) show how communities exposed to the Madoff Ponzi scheme withdrew assets from investment advisers and increased deposits at banks, and provide evidence that services which built up more trust experienced fewer withdrawals. Although their focus is money management, this is broadly consistent with the mechanism in our model that banks are trusted and that there will be flight towards more trusted entities following a loss of trust.
} 
the sense that it is easier to lose than to gain it.

Our theory is complementary to the "neglected risks" argument in Gennaioli, Shleifer, and Vishny (GSV, 2012, 2015b), who develop models of financial crises in which investors overweight "representative events" (based on the Kahneman and Tversky (1972) idea of "representativeness"), thereby underestimating security risk during good times. While their theory is about the security-related beliefs of investors, our theory is about lender-specific beliefs of investors. This leads to numerous differences. First, in the GSV models, when the neglected risks of a security are eventually recognized, all firms holding that security experience a negative shock. By contrast, in our model the loss of trust is a lender-specific phenomenon, so only the lenders suffering from a loss of trust are adversely affected. Second, in the GSV models, belief revisions are always non-Bayesian, whereas in our model belief revision coincides with Bayes rule in "normal" times (i.e. when there is uncertainty resolution within the initially-adopted model) and departs from it only for "unexpected" or zero-probability events (uncertainty resolution that rejects the initially-adopted model). ${ }^{16}$ Third, the GSV models predict that a crisis will be preceded by a sufficiently long string of bad news, whereas in our model a crisis can occur suddenly in an economic boom, with high defaults experienced by lenders. ${ }^{17}$ Finally, the prediction of our model about the asymmetry of lender trust is unique.

Our paper is part of a growing literature on the role of non-depository lenders vis a vis banks and how this is affecting the credit market. This literature is at present mainly empirical or descriptive. See, for example, Buchak et. al. (2017), Fenwick et. al. (2017), Greenwood and Scharfstein (2013), Phillipon (2016), and Zetzsche et. al. (2017). To the best of our knowledge, ours is the first paper to theoretically model trust-based intermediation and use it to characterize the impact of fintech firms on the credit market.

\footnotetext{
${ }^{16}$ The evidence provided by Weinstein (2011) is consistent with this kind of belief revision.

${ }^{17}$ In their model, investors use extrapolative expectations, so they initially under-react to bad news, but then over-react to it when there is a sufficiently long sequence of such news.
} 


\section{The Model}

There are two time periods. The first period begins at $t=0$ and ends at $t=1$, while the second period begins at $t=1$ and ends at $t=2$. All agents are risk neutral, and the one-period riskless rate is $r>0$. Since the riskless asset is accessible to all agents, the reservation rate of return on providing financing is $r$ for lenders as well as the financiers of lenders. That is, a lender can always obtain an expected return of $r$ by investing in the market. The economy has individual agents who can be borrowers or savers (or both), banks that intermediate between borrowers and savers by raising money from depositors and shareholders at $t=0$ and funding loans with that money, and (non-bank) fintech lending platforms that provide non-intermediated financing (e.g. P2P lending). While lenders (banks and fintech platforms) exist for both periods, each borrower, depositor, and shareholder lives for one period. Thus, there are first-period borrowers and financiers and second-period borrowers and financiers. This means all claims are settled at the end of each period and the only "long-lived" entity is the lender. This allows us to focus on the role of reputation and trust without complications from multiperiod debt contracting issues.

\subsection{Agents}

Borrowers: At the start of each period, there are agents who have projects, with each project requiring $L$ at the start of the period and paying off at the end of the period. The agents with projects are penniless and need loans to finance these projects - so we call them borrowers. Each borrower has a good (socially efficient) project that pays off $x \in \mathbb{R}_{+}$with probability $q \in(0,1)$ at the end of the period and 0 with probability $1-q$. The good project is therefore assumed to have a payoff of

$$
q x>L[1+r]
$$

A loan to a borrower with such a project is referred to as a " $G$ loan". 
The Loan Contract: Each first-period borrower takes a loan of $L$ at $t=0$ and promises to repay the lender some amount $R$ at $t=1$; this amount can be repaid only if the borrower's project pays off $x$. Thus, $q$ can also be viewed as a measure of the borrower's default risk, with higher $q$ implying lower default risk. Similarly, each second-period borrower takes a loan of $L$ and promises to repay some $R$ at $t=2$.

Depositors: These are agents who have liquidity at the start of each period that they can either deposit in a bank or invest in a riskless security that delivers a return of $r$. If an amount $D$ is deposited in the bank at $t=0$, it produces liquidity, safekeeping, and transaction services worth $\bar{\varphi}(D)>0 \forall D>0$ at $t=1$ if the bank is solvent and fully repays depositors, $\hat{\varphi}(D)>0 \forall D>0$ at $t=1$ if the bank fails and depositors are paid off by the insurer, and zero at $t=1$ if the bank fails and the depositors receive nothing. ${ }^{18}$ Here, $\bar{\varphi}(D)>\hat{\varphi}(D) \forall D>0, \bar{\varphi}^{\prime} \geq \hat{\varphi}^{\prime}>r$, and $\bar{\varphi}(0)=\hat{\varphi}(0)=0$. The same assumptions apply to second-period deposits that arrive at $t=1$ and are paid off at $t=2$. We take the available supply of deposits as exogenously fixed at $D<L$.

Depositors play two roles here - they provide financing and they consume services provided by the bank. As in Merton and Thakor (forthcoming), we refer to them as "customers" of the bank. This is in contrast to shareholders who are pure financiers of the bank. This is a feature that distinguishes banks from non-bank lenders-banks receive substantial financing from customers.

Banks: There are regulated entities that operate in a competitive credit market, designing loan contracts that maximize the expected utilities of borrowers subject to the participation constraints of depositors and investors. We assume that each bank is operated by a (penni-

\footnotetext{
${ }^{18}$ Donaldson, Piacentino, and Thakor (forthcoming) provide a foundational theory of banking in which banks exist to provide safekeeping depository services in an economy with no pledgeability of output. The notion that the value of depository services is lower when the bank fails and depositors are paid off than when the bank is solvent is meant to capture the idea that when a bank fails and the deposit insurer has to step in, there is some disruption in the services that depositors receive, some of it possibly arising from weaker incentives that a bank on the verge of insolvency will have in providing services to its customers (see Merton and Thakor (forthcoming)).
} 
less) insider who seeks to maximize his own expected utility. Each bank raises $D \in(0, L)$ in deposits at the start of each period and the rest of the needed funding from shareholders who require an expected return of $r$ on the funds they provide. Shareholders who provide funding at $t=0$ are paid off fully at $t=1$, conditional on the bank being solvent, at which time funds are raised from a new group of shareholders. Deposits are completely insured to guarantee depositors' payoff in the event of bank insolvency. ${ }^{19}$ If the bank is insolvent, the claims of the bank's shareholders are worthless, and after the depositors are paid of by the deposit insurer, equity financing for the second period is raised from a new group of shareholders. ${ }^{20}$ Without loss of generality, we set the deposit insurance premium at zero. ${ }^{21}$

Note that banks are raising all of their funding at $t=0$ from only two sources - deposits and equity. This is without loss of generality since our model distinguishes between deposits and funds provided by investors, but there is no difference between the expected returns that need to be provided to shareholders and subordinated debtholders, so the mix of equity and "sub" debt in the bank's capital structure is irrelevant. Financing to each bank is in perfectly elastic supply, and the return to each group of financiers satisfies the participation constraints of that group, i.e., gives that group an expected return of at least $r .^{22}$

Fintech Lenders: There is no intermediation with this form of lending and hence no depository services provided to customers. All financing is raised from investors (shareholders) and loaned to borrowers. That is, as in Philippon (2016), while banks are "levered lenders", fintech lenders such as P2P platforms are "all-equity" lenders. Each fintech platform is also operated to maximize the expected utility of the insider owner.

\footnotetext{
${ }^{19}$ This is for simplicity; our results are unchanged if we assume partial deposit insurance.

${ }^{20}$ That is, the previous shareholders of the failed bank no longer have any claim on the bank's cash flows.

${ }^{21}$ This is consistent with the institutional reality for U.S. banks over long periods of time. Moreover, as long as the premium is risk-insensitive, it reduces to a constant and does not affect the analysis.

${ }^{22}$ We will show later that the participation constraint of shareholders will hold tightly in equilibrium, whereas depositors' participation constraint will be slack.
} 


\subsection{Agent Types, Models of the World, and Uncertainties}

Models of the World: There are two models of the world that financiers (investors and depositors) can have: (1) lenders are trustworthy (Model I), and (2) lenders are self-interested (Model II). In Model I, the lender chooses to always make the $G$ loan. The lender's type in Model I is referred to as $\tau_{0}$. In Model II, the lender maximizes a type-dependent utlility function that could lead the bank to make a different loan.

There are three possible lender types in Model II: $\tau_{1}, \tau_{2}$, and $\tau_{3}$. All three types of lenders can invest in an inefficient loan ("PB" loan) in each period that generates a private benefit, $\tilde{\beta}$, in any period in which it is chosen. ${ }^{23}$ The choice of loan is unobservable. For type $\tau_{1}$, in any period $\tilde{\beta}_{1} \in\left\{\beta_{l}^{1}, \beta_{h}^{1}\right\}$, with $0<\beta_{l}^{1}<\beta_{h}^{1}$, with $\operatorname{Pr}\left(\tilde{\beta}_{1}=\beta_{1}^{l}\right)=\nu$, and $\operatorname{Pr}\left(\tilde{\beta}_{1}=\beta_{h}^{1}\right)=1-\nu$. For type $\tau_{2}$, in any period $\tilde{\beta}_{2} \in\left\{\beta_{l}^{2}, \beta_{h}^{2}\right\}$, with $\beta_{l}^{1}<\beta_{l}^{2}<\beta_{h}^{1}<\beta_{h}^{2}, \operatorname{Pr}\left(\tilde{\beta}_{2}=\beta_{l}^{2}\right)=\nu$, and $\operatorname{Pr}\left(\tilde{\beta}_{2}=\beta_{h}^{2}\right)=1-\nu$. In addition to generating these private benefits, the inefficient loan of types $\tau_{1}$ and $\tau_{2}$ pays off a pledgeable amount $x$ with probability $p<q$ and zero with probability $1-p$, with

$$
p x+\beta_{h}<L[1+r] .
$$

This means that the PB loan of type- $\tau_{2}$ is more attractive than that of type- $\tau_{1}$ when both have low private benefits and also when both have high private benefits. For type $\tau_{3}, \tilde{\beta}_{3}=B>\beta_{h}^{2}$ in any period. The PB loan for type- $\tau_{3}$ lender has a pledgeable payoff of zero almost surely. We assume that $B$ is so large that the type $\tau_{3}$ lender will always make the type- $\tau_{3}$ PB loan. ${ }^{24}$

Beliefs and Preferences: Conditional on the "correct" model of the world being Model II, the common prior belief of financiers and borrowers at $t=0$ is that $\operatorname{Pr}\left(\tau_{1}\right)=\gamma_{1} \in(0,1)$

\footnotetext{
${ }^{23}$ There are many ways to interpret $\tilde{\beta}$. One is that it is a private cost of monitoring the good loan that is avoided with the PB loan which pays the lender less because it is not monitored. The other is that it is literally a rent that accrues to the lender because the loan is made to a friend or relative of the manager of the lender.

${ }^{24}$ The reason for having type- $\tau_{3}$ in the model despite this is that in some of the equilibria we characterize, both types $\tau_{1}$ and $\tau_{2}$ choose the same strategies in the first period. This pooling means that the first-period outcome would not affect agents' perceptions of the lender's type in terms of distinguishing between $\tau_{1}$ and $\tau_{2}$. Having $\tau_{3}$ means that both $\tau_{1}$ and $\tau_{2}$ have a reputational incentive for avoiding default to separate from $\tau_{3}$.
} 
and $\operatorname{Pr}\left(\tau_{2}\right)=1-\gamma_{2}$ and $\operatorname{Pr}\left(\tau_{3}\right)=1-\gamma_{1}-\gamma_{2}$. In Model II, the lender has the following utility function in each period:

$$
u_{i j}^{t}=\alpha_{j}\left[1-s_{i}^{t}\right] z_{i j}^{t}+\left[1-\alpha_{j}\right] \tilde{\beta}_{j}
$$

where the superscript $t$ designates the time period, the subscript $j$ designates the lender's "type" in Model II - where $j \in\{1,2,3\}$ with $j=1$ designating $\tau_{1}, j=2$ designating $\tau_{2}$, and $j=3$ designating $\tau_{3}$-and $i \in\{b, f\}$ designates "bank" or fintech platform. In addition, $z_{i j}^{t}$ is the payoff to the shareholders of the lender, $s_{i}^{t}$ is the share of that payoff that the insider $i$ must sell to raise the equity needed in period $t$, and $\alpha \in(0,1)$ is a weighting factor.

The common prior belief of borrowers and financiers at $t=0$ is that the probability is $\zeta^{0} \in(0,1)$ that the true model of the world is Model I and $1-\zeta^{0}$ that it is Model II. Whatever model of the world is adopted by borrowers and financiers ("agents" henceforth when referred to collectively as a group), it applies to banks as well as fintech platforms. This "model uncertainty" plays a key role in the analysis.

Lender Maximization Programs and Information: Let $l_{i j}^{t} \in\{G, P B\}$ be the choice of loan in period $t$ by type $j \in\left\{\tau_{1}, \tau_{2}, \tau_{3}\right\}$ of lender $i \in\{b, f\}$ in Model II. Then in the second period:

$$
l_{i j}^{2} \in \arg \max _{\{G, P B\}} u_{i j}^{2}
$$

and in the first period:

$$
l_{i j}^{1} \in \arg \max _{\{G, P B\}} U_{i j}^{0}
$$

where

$$
U_{i j}^{0}=u_{i j}^{1}+\mathbb{E}\left[u_{i j}^{2}\left(l_{i j}^{2}\right)\right]
$$

is the expected utility of the bank decisionmaker over two periods, and it takes as a given the subgame perfect choice $l_{i j}^{2}$ in the second period. The maximizations above are subject 
to the participation constraints of the financiers of the lenders and borrowers.

We assume that while each lender can observe the borrowers' type, the lender's financiers cannot tell whether the lender made a $G$ or a PB loan.

Macro Uncertainty: The model also has a macro uncertainty whose realization is observed at the end of each period. The uncertainty represents the state of the overall economy, namely a systematic risk, and we delineate it as a random variable $\tilde{m}$ with probability density function $\eta$. Let $\operatorname{supp} \eta=[\underline{m}, \bar{m}]$. The realization of $\tilde{m}$ is publicly observed and has a multiplicative effect on the success probability of any investment by the lender. That is, there exists a function:

$$
C:[\underline{m}, \bar{m}] \times(0,1) \rightarrow(0,1)
$$

such that for a given $q \in(0,1)$ and a realized $m \in[\underline{m}, \bar{m}]$, the repayment probability of the good loan becomes $C(m, q) \in(0,1)$, with $\partial C / \partial m>0, C(\underline{m}, q)<q, C(\bar{m}, q)>q$. This means the better the macro state, the higher the success probability of the good project and hence the repayment probability of the good loan. Similarly, for the PB loan of the type $\tau_{1}$ lender in Model II,

$$
C:[\underline{m}, \bar{m}] \times(0,1) \rightarrow(0,1)
$$

and again for any $p \in(0, q)$, we have $\partial C / \partial m>0$.

Let

$$
\begin{aligned}
& \bar{q} \equiv \int_{\underline{m}}^{\bar{m}} C(m, q) \eta d m \\
& \bar{p} \equiv \int_{\underline{m}}^{\bar{m}} C(m, p) \eta d m
\end{aligned}
$$

Both (1) and (2) are assumed to hold with $\bar{q}$ and $\bar{p}$ replacing $q$ and $p$, respectively.

The Use of Model Uncertainty in the Equilibrium Concept: Introducing model uncertainty and using the equilibrium concept developed by Ortoleva (2012) allows us to model the possible loss of trust in lenders as a discontinuous shift in beliefs about their 
type or motives, as we explained in the Introduction. This sort of shift better captures loss of trust than would a smooth Bayesian revision of beliefs about types that is more the reputational effects frequently encountered in career-concerns models. ${ }^{25}$ Within-model uncertainty captures the normal Bayesian revision of beliefs about types that occurs once agents have (re)selected their model of the world based on their posterior beliefs about the lender's type. Since banks and fintech lenders are observationally distinct, revision of beliefs occurs for each as a distinct entity.

\subsection{Competitive Structure of the Credit Market}

Borrowers search for lenders. We assume that a borrower can find only one lender with probability $1-\theta$, and can find two or more lenders with probability $\theta \in(0,1)$. When the borrower can find two or more lenders, these lenders engage in Bertrand competition and the pricing of the loan is competitive, in that the lender's participation constraint holds tightly. When the borrower can find only one lender, the pricing is monopolistic, so the repayment obligation on the loan is set at the maximum pledgeable cash flow on the borrower's project, $x$. We can thus view $\theta$ as a measure of how competitive the credit market is, with higher values of $\theta$ representing greater credit market competitiveness. ${ }^{26}$ As mentioned previously, lenders are able to raise financing at competitive terms.

Bank Regulator: There is a regulator who provides complete deposit insurance. ${ }^{27}$ Although we take this as given, we also provide a microfoundation for it. In reality, insured banks are subject to a host of regulations that entail compliance costs. We ignore these for now but discuss their implications in a later section. Because fintech platforms do not have access to deposits, they are not subject to regulation.

\footnotetext{
${ }^{25}$ For example, Holmstrom and Ricart i Costa (1986).

${ }^{26}$ This specification is a way to provide for an ex ante sharing of the project surplus between the bank and the borrower. An alternative specification would be a Nash bargaining game.

${ }^{27}$ The justification for this specification is that depositor insurance is provided to enhance social welfare by insulating the bank's depository customers from the bank's credit risk (see Merton and Thakor (forthcoming)).
} 
Zero Lower Bound: We assume that all interest rates in the economy have a zero lower bound. ${ }^{28}$

\subsection{Summary of Timing and Actions}

There are two time periods, period 1 and period 2, and three dates: $t=0, t=1$, and $t=2$. At the start of each period, there are banks and fintech lending platforms that can potentially make loans to borrowers. The banks finance themselves in each period with a mix of deposits and equity. The deposits are completely insured, where $D$ is the amount of deposits raised and insured. The fintech platform finances itself entirely with equity raised from investors.

Economic agents can put their beliefs on two possible economic models of the world: that lenders are all trustworthy and will make good loans (Model I), or that lenders are selfinterested and will take into account their private benefits in choosing what loan to make (Model II). The beliefs of agents are common knowledge at $t=0$. These beliefs determine the costs of financing for lenders and hence the repayment obligations for borrowers in the first period.

At $t=0$, each borrower searches for a lender, and with probability $\theta$ it finds two or more lenders who are willing to lend, whereas with probability $1-\theta$ only one lender is found. The borrower cares only about the price of credit, not whether the lender is a bank or a fintech platform. Also at $t=0$, banks raise whatever financing they need from deposits and equity to make the first-period loan and satisfy regulatory capital requirements, and fintech platforms raise their necessary financing from investors. Then each lender privately observes its realized $\tilde{\beta}$ and chooses between the good loan and the PB loan, being aware that its financiers cannot tell whether it is a good loan or a PB loan. ${ }^{29}$

At $t=1$, the macro state $\tilde{m}$ is realized and it determines the success probability of

\footnotetext{
${ }^{28}$ This assumption helps to simplify the algebra, but is not crucial to the analysis. Essentially, it leads to depositors receiving a zero interest rate on deposits in equilibrium.

${ }^{29}$ If the bank wishes to make a PB loan, it does not approach a good borrower, so that borrower has no ability to learn the bank's "type".
} 
the loan made by the bank at $t=0$. The borrower repays or defaults on its loan and the lender settles the claims of its financiers, with the deposit insurer stepping in for the bank if the borrower defaults. Borrowers and financiers revise their beliefs about the true model of the world, and then arrive at their posterior beliefs about the lender's type within the model of the world chosen for the second period. Trust in lenders is either maintained or lost. This then determines each lender's cost of financing in the second period, and hence the price at which the second-period loan can be offered. It is possible that the first-period outcome is such that financiers are unwilling to provide second-period financing. That is, the first-period outcome may lead to a loss of trust that shuts out the lender in the second period. If lending occurs, then all second-period claims are settled at $t=2$. See Figure 1 which summarizes the sequence of events.

Note that all lenders start out with the same prior beliefs about whether they are trustworthy or self-interested, and the same prior beliefs over types conditional on being selfinterested. Hence, if Model I prevails, then all lenders are trusted at $t=0$, and if Model II prevails, then all lenders are considered self-interested at $t=0$. However, at $t=1$, whether an initially-trusted lender continues to be trusted depends on the information set at $t=1$, so some lenders may be trusted at $t=1$ and others may not be.

\section{Preliminary Analysis}

In this section we present some premliminary analysis. We start by describing the first best, then present results regarding the deposit interest rate and the extent of risk exposure for depositors. We then characterize the fintech platform's and the bank's loan obligations in the first-best case. This is followed by a discussion of the equilibrium. 
Figure 1: Time Line

\begin{tabular}{|l|l|l|}
\hline$t=0$ & $t=1$ & $t=2$ \\
\hline \hline Borrowers and financiers & T The macro uncertainty & Second-period claims are \\
share common prior beliefs & $\tilde{m}$ is realized and it affects & settled after second-period \\
about the true model of the & first-period success & $\tilde{m}$ is realized and loans are \\
world (i.e. the probability & probabilities. & repaid or default. \\
that lenders are & - Borrowers pay off or & \\
trustworthy) and the & default on first-period & \\
lender's type within each & loans. Lenders settle claims & \\
model. & with financiers. If the & \\
These beliefs determine & lender collects a profit, it is & \\
the prices at which banks & paid off to shareholders as & \\
and fintech lenders raise & a dividend. In the case of & \\
financing. & banks that fail, the deposit & \\
Each lender observes its & insurer covers part of the & \\
realized private benefit & claim. \\
from the PB loan and & - Economic agents revise & \\
decides whether to make & their beliefs about the true & \\
that loan or the good loan. & model of the world, and & \\
& their beliefs about lender & \\
& types within the model. & \\
& Lenders may lose trust. & \\
& Second period begins & \\
& with new borrowers and & \\
& new depositors. & \\
& Shareholders may or may & \\
& not choose to provide more & \\
financing. & \\
&
\end{tabular}




\subsection{First Best}

This is the case in which the borrower's project choice and the bank's loan choice are both observable. The first-best outcome can be trivially shown to be the bank making the good loan, and the borrower investing in the good project. Note that the first-best outcome for a single period is the same as the single-period outcome with trustworthy lenders. Next we have a useful result.

Lemma 1: The deposit interest rate is zero if we assume that depositors' financial claims are completely insulated from the bank's credit risk, i.e., deposits are riskfree.

The idea that depositors do not wish to be exposed to the bank's credit risk builds on the insights of Merton (1989, 1993, 1995, 1997), and most recently, Merton and Thakor (forthcoming). In the next result, we will establish that this is indeed the efficient outcome in our setting here.

The reason why the deposit interest rate is zero is that depositors receive bank services that are valued more highly, conditional on bank solvency, than the riskless rate $r$. Absent the zero lower bound on interest rates, depositors would even accept a negative interest rate. Thus, with a zero interest rate, the depositors receive an expected total return (including services) that exceeds their reservation expected return of zero (i.e. their participation constraint is slack).

Lemma 2: The social welfare benefit of the regulator providing complete deposit insurance relative to providing no insurance is

$$
[1-\bar{q}][\hat{\varphi}(D)-D]>0 .
$$

The intuition is that the value of depository services to the depositors when they are fully paid off in the state in which the bank fails is $\hat{\varphi}(D)$, and this exceeds the net cost 
of the provision of this insurance, $r D$. This makes it socially efficient for complete deposit insurance to be provided.

Next we turn to the borrower's first-best repayment obligations.

Lemma 3: The borrower's (first-best) repayment obligation when faced with only one lender $i s$ :

$$
R_{1}^{F B}=x
$$

and when faced with two or more lenders, it is:

$$
R_{2}^{F B}=\{L[1+r]\}\{\bar{q}\}^{-1}
$$

The repayment obligation offered is independent of whether the lender is a bank or a fintech lender.

This result follows from the fact that the lender fully extracts all project surplus when it is a monopolist, but offers a price to the borrower at which the loan yields an expected return of $r$ to the lender when there are two or more competing lenders. The reason why no lender prices the loan lower is that $r$ is each lender's reservation expected return on lending, since this is the return that can be obtained by investing in the riskless asset.

\subsection{Second Best: Equilibrium Concept}

We now define the equilibrium we will use to characterize the strategies of banks and fintech platforms in the second best. One of our main goals is to examine the role that financier trust plays in influencing lender behavior. Many seem to believe that the usurping of bank market share by fintech platforms is only the tip of the iceberg and that eventually banks will lose at least most of their transaction lending to their fintech rivals. Our point is that trust will be an important mediating variable in this dynamic and that banks have a potential advantage as "trusted lenders". 
As we discussed in the Introduction, trust is typically all-or-nothing - one either trusts an agent, or does not. So if we begin with a situation in which a lender is trusted and then we observe an outcome that seems patently incompatible with that trust, then we are essentially observing a zero-probability event, and Bayes rule for belief revision cannot be used.

To model such behavior and its implications for the strategies of lenders, we rely on Ortoleva's (2012) Hypothesis Testing Representation (henceforth HTR) to characterize belief revision. We embed this model in the definition of our equilibrium, which follows a discussion of how beliefs are formed and revised.

Discussion of Equilibrium Belief Formation: At $t=0$, all financiers and borrowers ("agents" henceforth) have common prior beliefs that if Model I is the true model of the world, then all lenders are trustworthy, and if Model II is the true model of the world, then there is a probability $\gamma_{1} \in(0,1)$ that the lender is of type $\tau_{1}$, a probability $\gamma_{2}$ that the lender is of type $\tau_{2}$, and a probability $1-\gamma_{1}-\gamma_{2}$ that the lender is type $\tau_{3}$. All financiers also have a prior over priors and believe that $\zeta^{0} \in(0,1)$ is the probability that Model I is the correct model and $1-\zeta^{0}$ is the probability that Model II is the correct model. In the first step, at $t=0$ the agents choose the model to which the prior over priors assigns the highest likelihood, i.e., they adopt Model I for their beliefs if $\zeta^{0} \geq 0.5$ and Model II if $\zeta^{0}<0.5$. They also choose the threshold probability $\varepsilon \in(0,1)$ for a future revision of their prior over priors. Given these beliefs, agents determine the price at which financing will be provided to lenders so as to yield each group of financiers an expected return of at least $r$, with the expectation taken over the beliefs adopted in Step 1.

At $t=1$, the macro state realization is observed and also whether the borrower has repaid or defaulted on the first-period loan. Based on this information, in Step 2 agents test their priors to determine if the correct model of the world was used in Step 1. If the probability that the agents' prior assigned to the observed repayment/default outcome at $t=1$ is above 
the threshold $\varepsilon$, then the prior belief chosen in Step 1 is not rejected, and beliefs are now updated using Bayes rule, thereby determining the second-period financing costs for lenders and the terms at which the lenders will make second-period loans to borrowers.

If, however, the probability that the agents' prior assigned to the new information observed at $t=1$ is below the threshold $\varepsilon$, then the prior is rejected and agents go back to their prior over priors $\zeta^{0}$, update it using Bayes' rule using the information at $t=1$, and then in Step 3 chooses the prior to which the updated prior over priors assigns the highest likelihood. With these new beliefs, financiers determine the cost at which lenders can raise financing, and lenders determine the terms at which they will lend to second-period borrowers. A visualization of this process is provided in Figure 2.

This means that if the prior "chosen" at $t=0$ is rejected by the data, agents reconsider the prior to use by choosing the new maximum likelihood prior, which is extracted by examining the prior over priors after its updating using Bayes' rule. The idea is that $\varepsilon$ is some arbitrarily small positive number, and we will assume throughout that this is the case. As Ortoleva (2012) points out, when $\varepsilon=0$, belief revision is exactly in accordance with Bayes' rule. ${ }^{30}$

Note that in our setting, a model is itself a prior belief over the lender's type, and $\zeta$ is the prior over these prior beliefs. Using Ortoleva's (2012) notation, we therefore define $\pi$ as the prior belief, which in our model is a vector of two probability distributions over lender types, $\pi=\left\{\pi_{T}, \pi_{N}\right\}$, where

$$
\begin{gathered}
\pi_{T}=\left\langle\operatorname{Pr}\left(\tau_{0}\right)=1, \operatorname{Pr}\left(\tau_{1}\right)=0, \operatorname{Pr}\left(\tau_{2}\right)=0, \operatorname{Pr}\left(\tau_{3}\right)=0\right\rangle \\
\pi_{N}=\left\langle\operatorname{Pr}\left(\tau_{0}\right)=0, \operatorname{Pr}\left(\tau_{1}\right)=\gamma_{1} \in(0,1), \operatorname{Pr}\left(\tau_{2}\right)=\gamma_{2} \in(0,1), \operatorname{Pr}\left(\tau_{3}\right)=1-\gamma_{1}-\gamma_{2} \in(0,1)\right\rangle,
\end{gathered}
$$

where $\tau_{0}$ denotes that the lender is trustworthy, $\tau_{i}$ denotes that the lender is self-interested and of type $\tau_{i}$, with $i \in\{1,2,3\}$. Then the prior over priors says that $\zeta^{0}$ is the prior belief

\footnotetext{
${ }^{30}$ See Ortoleva (2012) for an analysis of the uniqueness properties of this representation.
} 


\section{Figure 2: Hypothesis Testing Representation}

\section{STEP 1}

- All agents

(financiers) start with prior over priors about the right model of the world

- The model assigned the highest likelihood by the prior over priors is adopted as the model of the world

- A threshold probability $\varepsilon>0$ is assigned for hypothesis testing

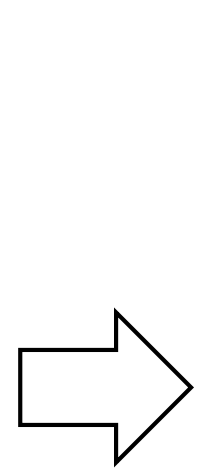

\section{$\underline{\text { STEP } 2}$}

- Outcomes observed

- Agents test their initial hypothesis that their chosen model was correct

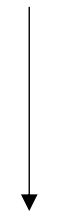

Based on initial model, did observed outcome have probability of occurrence $>\varepsilon$ ?

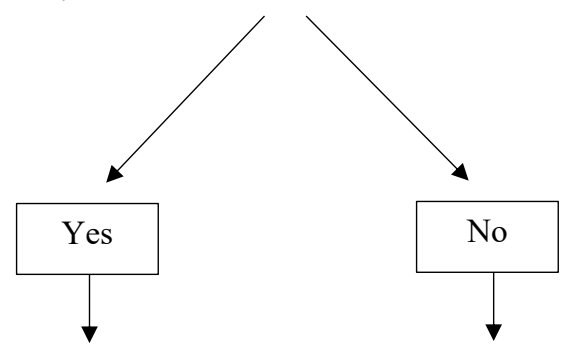

Reject initial prior and

Do not reject initial model and revise beliefs using Bayes' Rule go back and revise prior over priors using Bayes

Rule and observed outcome at $t=1$

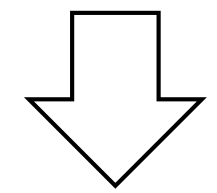

\section{STEP 3}

- Choose the model to which the updated prior over priors assigns the highest likelihood 
that the correct prior is $\pi_{T}$ and $1-\zeta^{0}$ is the prior belief that the correct prior is $\pi_{N}$.

Before we define the equilibrium formally, some additional notiation is useful. We will use the time superscript on the prior to designate the date at which the prior is chosen, i.e., $\pi^{0}$ is the prior chosen at $t=0$ and $\pi^{1}$ the prior chosen at $t=1$. We will use the same date nomenclature in assigning superscripts to all the other variables. Let $\omega$ be the observed outcome at $t=1$, where $\omega$ is the realization of a pair of random variables: $\omega=$ $\{$ borrower defaults or repays, $m$ \}. Let $\Omega$ be the set of $\omega$ 's for all lenders.

Definition of Competitive Equilibrium: A competitive equilibrium consists of a vector of beliefs, prices, and strategies at $t=0$ and a vector of beliefs, prices, and strategies at $t=1$ that can be described as follows:

At $t=0$, the equilibrium consists of $\left\langle\varepsilon, \pi^{0}, R_{1}^{0}, R_{2}^{0}, \phi_{i}^{0}\left(\tau_{j}\right)\right\rangle$ where it is common knowledge that $\varepsilon$ is the threshold probability chosen by agents, $\pi^{0} \in\left\{\pi_{T}, \pi_{N}\right\}$ is the prior belief chosen by agents over lenders' types, $R_{1}^{0}$ and $R_{2}^{0}$ are the repayment obligations of the borrower when faced with a single lender and when faced with two or more lenders, respectively, $\phi_{i}^{0}\left(\tau_{j}\right)$ is the strategy of a lender $i \in\{b, f\}$ of type $\tau_{j}, j \in\{0,1,2,3\}$, where the lender's strategy is a choice of loan from $\{G$, $\mathrm{PB}$, conditional on making a loan, as well as the decision of whether to make a loan. Here $\pi^{0}$ is chosen by agents using the HTR; and $\phi_{i}^{0}$ is chosen by each lender to maximize its expected utility over two periods, given $\pi^{0}$ and $\pi^{1}(\omega)$ in each future $\omega \in \Omega .^{31}$

(ii) $\quad$ At $t=1$, each $\omega \in \Omega$, the equilibrium consists of $\left\langle\pi^{1}(\omega), R_{1}^{1}, R_{2}^{1}, \phi_{i}^{1}\left(\tau_{j}\right)\right\rangle$, where $\pi^{1}(\omega) \in\left\{\pi_{T}, \pi_{N}\right\}$ is the updated prior belief over lenders' types chosen by agents at $t=1$ based on the HTR; $R_{1}^{1}$ and $R_{2}^{1}$ are the repayment obligations of the borrower in the second period when finding only one lender and when it finds two or more lenders, respectively; and $\phi_{i}^{1}\left(\tau_{j}\right)$ is the strategy of a lender in the second

\footnotetext{
${ }^{31}$ Agents here are all financiers of lenders and those who borrow from the lenders.
} 
period, defined in a manner similar to $\phi_{i}^{0}\left(\tau_{j}\right)$. Note that $\phi_{i}^{1}\left(\tau_{j}\right)$ also includes not extending a loan because the lender may be unable to raise financing at $t=1$. All strategies are subgame perfect in the sense that: the lender's choice of loan solves (4) and the loan prices is determined as in Lemma 3, subject to the participation constraints of lenders' second-period financiers, taking $\pi^{1}(\omega)$ as given.

Our focus in the analysis will be on a situation in which agents use the HTR and at $t=0$ choose the prior that lenders are trustworthy. ${ }^{32}$ We will then examine the behavior of banks and fintech platforms in the first period when they are trusted. This allows us to characterize conditions under which trust can be lost in the second period, which then leads to an analysis of how the potential to lose trust in the future influences lender behavior at $t=0$.

\section{Analysis of the Second-Best Equilibrium with Trust}

\subsection{Evolution of Beliefs and Trust}

In this section, we solve for the equilibrium. We establish four general results about trust, how it can be lost, and how banks have an advantage over fintech platforms because of their traditional role as trusted lenders. Our first result has to do with how a lender chooses its second-period strategy, conditional on the strategy it chose in the first period and the first-period outcome.

In preparation for this result, we need to introduce some notation. Recall that $\zeta^{1}$ is the prior over priors at $t=1$ and $\pi^{1}(\omega)$ is the prior belief chosen by agents at $t=1$ using the

\footnotetext{
${ }^{32}$ In a sense, we can think of this as corresponding to the current credit market situation in which lenders are trusted by financiers to make good loans.
} 
HTR. Thus, using the notation from (14) and (15): ${ }^{33}$

$$
\pi^{1}(\omega)= \begin{cases}\pi_{T} & \text { if agents believe lender is trusted } \\ \pi_{N}=\left\langle\mu_{\omega}^{i}(1), \mu_{\omega}^{i}(2), 1-\mu_{\omega}^{i}(1)-\mu_{\omega}^{i}(2)\right\rangle & \text { if agents believe at } t=1 \\ & \text { that lender is self interested }\end{cases}
$$

where

$$
\mu_{\omega}^{i}(j) \equiv \operatorname{Pr}\left(\text { lender } i \text { is type } \tau_{j} \mid \pi^{2}=\pi_{N}, \omega, j=1,2\right)
$$

where $i \in\{b, f\}$, and recall that $\omega \in \Omega$ is the composite state that includes the realized $\tilde{m}$ and whether the first-period borrower repaid the loan or defaulted. To simply notation, let $\mu_{\omega}^{i}(3)=1-\mu_{\omega}^{i}(1)-\mu_{\omega}^{i}(2)$.

We now introduce some additional notation that is useful in the subsequent analysis. Let $\lambda_{i}$ (with $i \in\{b, f\}$ ) be the net payoff to the lender's shareholders when the $G$ loan repays, and define an indicator function indicating that Model I is chosen:

$$
I_{\left\{\pi_{T}\right\}}^{t}= \begin{cases}1 & \text { if } \pi^{t}(\omega)=\pi_{T}, t \in\{0,1\} \\ 0 & \text { otherwise }\end{cases}
$$

and an indicator function related to the choice of the $G$ loan:

$$
I_{i}^{t}(j)= \begin{cases}1 & \text { if the strategy } \phi_{i}^{t}\left(\tau_{j}\right) \text { chooses the } G \text { loan } \\ 0 & \text { otherwise }\end{cases}
$$

Note that

$$
\begin{gathered}
\lambda_{b}=\theta R_{2}^{F B}+[1-\theta] x-D \\
\lambda_{f}=\theta R_{2}^{F B}+[1-\theta] x
\end{gathered}
$$

\footnotetext{
${ }^{33}$ Specifically, $\pi_{i}=\left\langle\operatorname{Pr}_{i}\left(\tau_{0}\right), \operatorname{Pr}_{i}\left(\tau_{1}\right), \operatorname{Pr}_{i}\left(\tau_{2}\right)\right\rangle \forall i \in\{1,2\}$.
} 
where $R_{2}^{F B}$ is available in (13). Both the bank and the fintech lender need to raise equity financing to fund the loan. Let $s_{i}^{t}(\omega), i \in\{b, f\}$, be the share of ownership that a type- $i$ lender must sell in order to raise the financing needed at $t \in\{0,1\}$ when the state $\omega$ is observed (this observation is only relevant for $t=1$ ). We now have the following result:

Lemma 4: $R_{1}^{t} \equiv R_{1} \equiv R_{1}^{F B}=x \forall t \in\{0,1\}$ and $R_{2}^{t} \equiv R_{2}=R_{2}^{F B}=\{L[1+r]\}\{\bar{q}\}^{-1} \forall$ $t \in\{0,1\}$. Moreover, for any set of beliefs about the lender's type, in each period we have:

$$
\begin{aligned}
s_{b}^{t}(\omega) & =\frac{[L-D][1+r]}{\left[\bar{q} I_{\left\{\pi_{T}\right\}}^{t}+\left[1-I_{\left\{\pi_{T}\right\}}^{t}\right] \sum_{j=1}^{3} \bar{q} \mu_{\omega}^{b}(j) I_{b}^{t}(j)\right] \lambda_{b}} \\
s_{f}^{t}(\omega) & =\frac{L[1+r]}{\left[\bar{q} I_{\left\{\pi_{T}\right\}}^{t}+\left[1-I_{\left\{\pi_{T}\right\}}^{t}\right] \sum_{j=1}^{3} \bar{q} \mu_{\omega}^{f}(j) I_{f}^{t}(j)\right] \lambda_{f}}
\end{aligned}
$$

where $\mu_{\omega}^{i}(j)$ is defined in (17).

This lemma says that the borrower's repayment obligation depends only on whether there is just one lender or there are two or more lenders. This is because that is the only factor that affects loan pricing. Investors' beliefs about the bank's type affect the cost and availability of funds as well as the lender's participation constraint, but not loan pricing. That is, investors' beliefs influence the shares of ownership that lenders must sell to raise financing for the loan.

Theorem 1: Suppose that lenders start out at $t=0$ with agents choosing

$$
\zeta^{0} \in\left(0.5,\left[1-\bar{\mu}_{\bar{m}} C(\bar{m}, q)\right][2-\bar{\mu} C(\bar{m}, q)-C(\bar{m}, q)]^{-1}\right)
$$

where

$$
\bar{\mu}_{\bar{m}} \equiv \sum_{j=1}^{2} \frac{[1-C(\bar{m}, q)] \gamma_{j}}{[1-C(\bar{m}, q)] \sum_{j=1}^{2} \gamma_{j}+1-\gamma_{1}-\gamma_{2}}
$$

Then lenders will be viewed as trustworthy at $t=0$ under the HTR. Whether they lose this trust at $t=1$ is sensitive to the realization of $\tilde{m}$ and whether the lender experiences default. 
Trust will not be lost if the borrower repays the lender at $t=1$, but it may be lost if the lender experiences default, depending on $\tilde{m}$. If

$$
1-C(\bar{m}, q)<\varepsilon<1-C(\underline{m}, q)
$$

then $\exists m^{*} \in(\underline{m}, \bar{m})$ such that a lender that experiences borrower default at $t=1$ will lose trust in the second period if $m>m^{*}$ and not lose trust if $m \leq m^{*}$.

This result shows that lenders that fail at the end of the first period are more likely to lose trust if the failure occurs when the macroeconomic state is better. ${ }^{34}$ The intuition is that even a good loan is more likely to default in a recession than in a boom, so the hypothesis testing under the HTR at $t=1$ will reject the initial prior over priors that led agents to view the lender as trustworthy in the first period when the bank fails in a boom, but may not do so in a recession. We next have a corollary of this theorem.

Corollary 1: Suppose $\zeta^{0}$ is as in (24)-(26) holds. Then, conditional upon experiencing borrower default at $t=1$ : (i) in states $m>m^{*}$, all lenders experiencing default lose trust; and (ii) in states $m \leq m^{*}$, no lender experiencing default loses trust.

The intuition is that if agents believe that lenders are trustworthy in the first period, then they are believed to have made $G$ loans in the first period. The probability of failure with the $G$ loan is the same for every lender. Hence, the HTR either rejects the initial prior over priors for all lenders experiencing default or for none. Note that since the $G$ loans have outcomes that are not perfectly correlated, at $t=1$ there are lenders who experienced default and lenders that did not. Hence, at $t=1$, it is possible to have some lenders who are trusted and some who are not. Henceforth, we will assume that (24) and (26) hold.

Theorem 2: Conditional on being funded, for any set of beliefs of investors about the bank's type, the following are true:

\footnotetext{
${ }^{34}$ Note that $(26)$ is not a very restrictive condition. It simply states that $[C(\underline{m}, q), C(\bar{m}, q)]$ is a sufficiently large subset of $[0,1]$.
} 
(i) A bank and a fintech lender have the same incentive to choose loan $G$ if both are type $\tau_{0}$ (Model I); and

(ii) A bank always has a stronger incentive to make (higher profitability from making) the $G$ loan than does a fintech lender, conditional on both being type $\tau_{i}, i \in\{1,2\}$ (in Model II), and have the same incentive if both are type $\tau_{3}$.

This result says that, when it comes to choosing between a $G$ loan and a PB loan, a self-interested bank always has a stronger incentive than a self-interested fintech lender to make the $G$ loan, as long as it is type $\tau_{1}$ or $\tau_{2}$. If they are type $\tau_{3}$, then they clearly have the same incentive to choose the PB loan.

This result arises from the access that banks have to insured deposits and the valuable services they provide to depository customers. The surplus generated by these services gives banks a powerful incentive to make the efficient $(G)$ loan. This result will play a central role in the subsequent analysis.

\subsection{Lender Strategies}

We now turn to the strategies of lenders starting with the second period. Before this analysis, we state some restrictions on the parameter values; the formal expressions related to these restrictions are placed in the Appendix.

Restriction 1: The bank's incremental expected utility from investing in the $G$ loan relative to the $\mathrm{PB}$ loan at the first-best financing cost is between the high private benefits of the PB loans of the type- $\tau_{1}$ and type- $\tau_{2}$ banks. In addition, the high private benefit of the type- $\tau_{2}$ bank is not excessively high.

This is essentially a restriction on the private benefits of the PB loan for the type- $\tau_{1}$ and type- $\tau_{2}$ banks. Having type- $\tau_{1}$ lenders have lower private benefits is one of the key features distinguishing the type- $\tau_{1}$ lenders from type- $\tau_{2}$ lenders. Moreover, if the private benefit of the PB loan for the type- $\tau_{2}$ is too high, this type would be indistinguishable from the type- $\tau_{3}$ 
lender.

Restriction 2: The fintech lender's incremental expected utility from investing in the $G$ loan relative to the $\mathrm{PB}$ loan at the first-best financing cost is high in value relative to the low private benefit of the $\mathrm{PB}$ loan for the type- $\tau_{1}$ lender, and low in value relative to the low private benefit of the type- $\tau_{2}$ lender. Moreover, the high private benefit of the type- $\tau_{1}$ lender is not too high, but the high private benefit of the type- $\tau_{2}$ lender is high relative to the fintech lender's utility.

This is a restriction on the private benefits of the PB loan for the type- $\tau_{1}$ and type- $\tau_{2}$ fintech lenders, similar to Restriction 1 for banks. From Theorem 2, we know that a bank has a stronger incentive to make a $G$ loan than a fintech lender does, which is reflected in Restrictions 1 and 2.

Restriction 3: The bank's incremental expected utility from investing in the $G$ loan relative to the PB loan at the second-best (no trust) financing cost is high relative to the high private benefit of the PB loan for the type- $\tau_{1}$ bank.

This is a restriction on the high private benefit of the type- $\tau_{1}$ bank relative to the bank's incremental expected utility from investing in the $G$ loan at a financing cost higher than the second-best. If such a restriction were not in place, no bank (or any other type of lender) would be able to operate when there is no trust.

Restriction 4: Investors' prior belief that the lender is type- $\tau_{1}$ and the success probability of the $G$ loan are intermediate in value.

The reason for this condition is as follows. Lenders lose trust at the beginning of the second period (assuming they had it in the first period) only if they experience defaults on first-period loans. This restriction ensures that, conditional on losing trust, the posterior probability that the lender is type- $\tau_{1}$ is neither too high nor too low. We wish to focus on separating equilibria in which second-period lending strategies differ based on lender type and loss of trust is consequential in terms of an increase in funding costs and possibly lack 
of access to second-period funding. Since the type- $\tau_{1}$ lender makes prudent loans in more states of the world than the other types, if the posterior probability of type $\tau_{1}$ is too high, the loss of trust will have little impact on access to financing and its cost. If the posterior probability of type $\tau_{1}$ is too low, all lenders will get shut out of the market in the second period. Restriction 4 helps us to focus on the (subgame perfect) Nash equilibria of interest.

Lemma 5: Suppose agents adopt Model I and lenders are trusted in the second period (at $t=1)$. Then the optimal second-period strategies of lenders in equilibrium are as follows:

\begin{tabular}{|c|c|c|}
\hline Bank/Fintech & Lender's Type & Lending Strategy \\
\hline \hline \multirow{2}{*}{ Bank: } & $\tau_{0}$ & $G$ with probability 1 \\
& $\tau_{1}$ & $G \forall \beta \in\left\{\beta_{l}^{1}, \beta_{h}^{1}\right\}$ \\
& $\tau_{2}$ & $G$ for $\beta=\beta_{l}^{2}$ and $P B$ for $\beta=\beta_{h}^{2}$ \\
& $\tau_{3}$ & $P B$ with probability 1 \\
\hline \multirow{3}{*}{ Fintech Lender: } & $\tau_{0}$ & $G$ with probability 1 \\
& $\tau_{1}$ & $G$ for $\beta=\beta_{l}^{1}$ and PB for $\beta=\beta_{h}^{1}$ \\
& $\tau_{2}$ and $\tau_{3}$ & $P B$ with probability 1 \\
\hline
\end{tabular}

The intuition for this lemma comes from Theorem 2. When lenders are trusted, they can raise funding at the lowest cost possible because investors believe that the $G$ loan will be made with probability 1 . In other words, each lender has the highest expected second-period surplus from making the $G$ loan under these circumstances. Nonetheless, given Theorem 2, we also know that a type $\tau_{i}(i \in\{1,2\})$ bank always finds it more profitable to make the $G$ loan than a type $\tau_{i}$ fintech lender does. Thus, the set of states in which a type $\tau_{i}(i \in\{1,2\})$ bank makes the $G$ loan is no smaller than the set of states in which a type $\tau_{i}$ fintech lender makes the $G$ loan, and for some sets of parameter values, the set of states in which the bank makes the $G$ loan is strictly larger.

The next result deals with what happens in the second period if there is no trust: 
Lemma 6: Suppose agents adopt Model II and lenders are not trusted in the second period $($ at $t=1)$. Then the optimal stategies of lenders in the second period are as follows:

\begin{tabular}{|c|c|c|}
\hline Bank/Fintech & Lender's Type & Types of Loan Made \\
\hline \hline \multirow{2}{*}{ Bank: } & $\tau_{0}$ & G with probability 1 \\
& $\tau_{1}$ & G for $\beta=\beta_{l}^{1}$ and PB for $\beta=\beta_{h}^{1}$ \\
& $\tau_{2}$ and $\tau_{3}$ & $P B$ with probability 1 \\
\hline \multirow{2}{*}{ Fintech Lender: } & $\tau_{0}$ & $G$ with probability 1 \\
& All $\tau_{i}, i \in\{1,2,3\}$ & PB with probability 1 \\
\hline
\end{tabular}

Consequently, conditional upon loss of trust, banks will be able to raise second-period financing. But fintech lenders that have lost trust will be unable to raise second-period financing.

This lemma has two striking implications. The first is that banks may be able to weather a loss of trust, but fintech lenders cannot. The second is that reputation becomes important when trust is lost. In a sense, trust insulates lenders against the adverse reputational consequences of bad outcomes. But once that shield is lost, the lender needs a sufficiently strong reputation to survive.

Comparing Lemmas 5 and 6, we see that agents' beliefs about whether lenders are trustworthy or self-interested affect the equilibrium strategies of lenders. The reason is that these beliefs then impact the attractiveness of the $G$ loan relative to the PB loan. When lenders are not trusted, their financing costs are higher than when they are trusted. This means that the PB loan is preferred by lenders in more states of the world when lenders are trusted than when they are not. Thus, lenders make the $G$ loan in fewer states when there is no trust than when there is trust.

\subsection{First-period Strategies and Overall Equilibrium}

We can now characterize the overall equilibrium, including first-period strategies.

Theorem 3: Suppose agents adopt Model I and lenders are trusted in the first period (at 
$t=0)$. Then there exists $\underline{m}$ high enough such that lenders choose the following strategies in the first period:

\begin{tabular}{|c|c|c|}
\hline Bank/Fintech & Lender's Type & Lending Strategy \\
\hline \hline \multirow{2}{*}{ Bank: } & $\tau_{0}$ & $G$ with probability 1 \\
& $\tau_{1}$ and $\tau_{2}$ & G with probability 1 \\
& $\tau_{3}$ & $P B$ with probability 1 \\
\hline \multirow{3}{*}{ Fintech Lender: } & $\tau_{0}$ & $G$ with probability 1 \\
& $\tau_{1}$ & $G$ with probability 1 \\
& $\tau_{2}$ & $G$ for $\beta=\beta_{l}^{2}$, PB for $\beta=\beta_{h}^{2}$ \\
& $\tau_{3}$ & $P B$ with probability 1 \\
\hline
\end{tabular}

If a lender makes a loan at $t=0$ that repays at $t=1$, trust is maintained in the second period. Similarly, if $m \leq m^{*}$ (Theorem 1) and a loan made at $t=0$ defaults at $t=1$, trust in the lender is maintained in the second period. In this case, the lender's second-period strategies are as described in Lemma 5. If a lender makes a loan at $t=0$ that defaults at $t=1$ and $m>m^{*}$, trust is lost in the second period. In this case, the lender's second-period strategies are as described in Lemma 6.

This theorem reveals an intuitive result, which is that a self-interested lender makes the $G$ loan in more states of the world in the first period when it is trusted than in the second period when it is trusted. The reason, of course, is that maintaining trust through its firstperiod lending strategy has value in terms of reducing the cost of second-period financing; this added value is absent in the second period because it is the last period. That is, investor trust has a stronger incentive effect on the lender when there are more periods to go.

Next we turn to the nature of the equilibrium when there is no trust in the first period.

Theorem 4: Suppose agents adopt Model II at $t=0$ and lenders are not trusted. Also assume that it is impossible to become trusted at $t=1$ if the lender started out not being trusted at $t=0$. Then for $\underline{m}$ high enough, in equilibrium banks are able to raise financing 
at $t=0$ and they have the following equilibrium strategies in the first period:

\begin{tabular}{|c|c|}
\hline Bank Type & Lending Strategy \\
\hline \hline$\tau_{0}$ & $G$ with probability 1 \\
$\tau_{1}$ & $G \forall \beta \in\left\{\beta_{l}^{1}, \beta_{h}^{1}\right\}$ \\
$\tau_{2}$ & $G$ for $\beta=\beta_{l}^{2}, P B$ for $\beta=\beta_{h}^{2}$ \\
$\tau_{3}$ & $P B$ with probability 1 \\
\hline
\end{tabular}

No fintech lender is able to raise financing at $t=0$.

This theorem asserts that trust is important for all lenders, but it is essential for fintech lenders to operate. This result is an extension of Lemma 6, but it goes further-a fintech lender will not even be able to begin to operate at $t=0$ if there is no trust. The intuition is as follows. We know from Lemma 6 that if a fintech lender is not believed to be trustworthy at $t=1$ by investors, then investors will not be willing to finance it. Given the assumption that a lender who is not trusted at $t=0$ will not be able to gain trust at $t=1$, the fintech lender knows at $t=0$ that it will be out of the market in the second period regardless of the first-period outcome. Hence, its lending strategy at $t=0$ is a single-period strategy, identical to its second-period strategy. Since it is unable to raise financing with this strategy in the second period, it is also unable to raise financing in the first period.

In Theorem 4, it was assumed that if lenders start out not having the trust of investors, then it is impossible for them to win that trust in the second period. In our next result, we validate this assumption.

Theorem 5: Consider parameter values such that in equilibrium, lenders start out being trusted at $t=0$ and lose trust at $t=1$. Then, for the same parameter values, lenders can never regain trust at $t=1$ if they start out being considered self-interested at $t=0$.

This result shows that trust can be asymmetric - it is easier to lose trust that exists than to gain trust when it does not exist in the first place. The intuition is as follows. Suppose lenders do not have trust at $t=0$, and the equilibrium at $t=0$ is one in which the type- $\tau_{1}$ 
lenders make good loans for all realizations of its private benefit from the PB loan. Then if the lender experiences loan repayment at $t=0$, it may merely "confirm" that the lender is a type- $\tau_{1}$ lender, especially if the prior probability attached to the lender being type- $\tau_{1}$ was high, i.e., if it had a strong reputation ex ante. And of course this reputation must be high enough or else the lender would not have been able to raise financing at $t=0$. In other words, the HTR will not reject the initial model II based on the repayment outcome. Thus, a lender with a strong reputation but no trust is unable to become trusted by experiencing good outcomes. However, if it starts out with trust and experiences borrower default, the HTR may reject the initial Model I and trust will be lost.

\section{Model Extensions and Discussion}

In this section, we explore extensions of the model which introduce additional differences between banks and fintech firms. We also provide a discussion of additional applications of the model, and suggestions for future work.

\subsection{Regulatory and Technological Costs}

In our main model, the key difference between banks and fintech lenders is that banks are able to obtain funding via deposits, while fintech lenders are all-equity financed. We showed that this gives banks a funding-cost advantage, as well as endogenous incentives to maintain trust. In practice, fintech firms also have other potential cost advantages which may partially offset this advantage of banks. One such advantage is lower regulatory costs-banks are regulated entities, whereas fintech lenders such as P2P platforms are not. ${ }^{35}$ Another cost advantage may come from more effective utilization of information technology, that may allow fintech

\footnotetext{
${ }^{35}$ While there are some regulations that affect these platforms, they are far less than what banks face. Each U.S. state has different rules for the regulation of P2P borrowers and investors. Residents of all states except Iowa, Maine, and North Dakota can apply for P2P loans, whereas investors in 30 states can invest in Prosper loans and investors in 26 states can invest in Lending Club. Other than being "accredited investors" ( $\$ 1$ million or more in new worth), there are no specific regulations on these investors. See Knowledge@Wharton, January 8, 2014.
} 
lenders to have a borrower screening advantage over banks (see Buchak, Matvos, Piskorski, and Seru (2017) for evidence). ${ }^{36}$

If a fintech lender has a cost of operating its lending platform that is lower than the regulatory and operating costs that banks face, there will be no effect on loan interest rates offered to borrowers as long as lenders can still lend profitably. However, the difference between the profit margins of banks and fintech lenders will decline. This means that there will be a relative decline in the role of banks as "trusted lenders". Thus, high regulatory costs can reduce a key competitive advantage of banks. Moreover, regulatory costs for banks are typically higher for riskier loans. This means that these are the loans for which the relative advantage of banks over fintech lenders will decline the most when regulatory costs are introduced. The implication is that it is the riskiest loans that fintech lender are most likely to lure away from banks - for these loans, banks are not able to offer competitive terms compared to fintech lenders. ${ }^{37}$

\subsection{Trust, Transparency, and Opacity}

In our analysis, the key informational assumption is that the lender's asset choice is unobservable to its investors and the regulator. In reality, lenders face reporting requirements as well as regulatory monitoring that can reduce opaqueness and shed light on the lender's asset choice. Moreover, lenders themselves can choose to voluntarily become more transparent by choosing to disclose more information. How does transparency interact with trust?

The answer depends on the nature of the loans the lender is making. If investors can, at

\footnotetext{
${ }^{36}$ As Buchak et al. (2016) point out, one of the factors that has facilitated the growth of fintech is information technology, including techniques to analyze big data. Such automated credit analysis does not rely on the generation and interpretation of soft information that has been a competitive advantage for many (especially small) banks. In fact, Buchak et al. (2016) point out that fintech platforms appear to be more proficient than banks in analyzing big data relating to borrower default risk. It should be noted that while banks have been making an effort to adopt the same technology as fintech firms, fintech firms still in general have an technology advantage.

${ }^{37}$ There is one caveat to this. If the higher regulatory costs that banks face are due to more stringent regulatory monitoring, then holding everything all else constant, there would be less moral hazard in lending with banks than with fintech lenders. This can offset the adverse impact of regulatory costs on banks' incentives to be trustworthy.
} 
relatively low cost, understand the quality of the lender's loans (and other assets, if any) with sufficient information disclosure, then the lender can reassure investors that it is investing in a good loan simply by disclosing enough information. In this case, transparency can substitute for trust. Thus, in cases in which specialized expertise is not needed to understand disclosed information about a lender's activities, transparency and trust are substitutes.

However, an implicit assumption in our analysis is that the loans made by banks and fintech platforms are inherently opaque in the sense that risk-shifting is difficult (or prohibitively costly) to detect even with a great deal of information disclosure. A substantial amount of expertise/judgment may be needed to process and interpret the information, and even then it may be quite costly. In such cases, transparency does not substitute for trust. In other words, when assets are innately opaque and it takes both expertise and significant costs to process any information disclosed about the assets - the setting in this paper - a lender cannot overcome lack of trust simply by being more transparent.

Our analysis of lender trust thus provides a different perspective on bank opaqueness from that in earlier research. Bhattacharya and Chiesa (1995) propose that banks choose to be opaque because they seek to protect the confidentiality of their borrowers' information. Dang, Gorton, Holmstrom, and Ordonez (2017) argue that banks are opaque because disclosing information would expose initial uninsured depositors to unwanted (price) risk. Our point is different. Trusted banks can "afford" to be opaque, and if there is any cost associated with transparency — even if very small — trusted banks will strictly prefer to be opaque. In contrast, lenders lacking trust may choose transparency.

To sum up, when disclosed information can be processed by investors at a low cost, the value of trust is relatively low because trust and informational transparency are partial substitutes. In this case, the market segments into trusted lenders who are opaque and other lenders who are transparent. But when information is very costly to process, all lenders remain opaque and the value of trust is high, with the trusted lenders having a significant funding cost advantage over others. 
This market segmentation potentially applies to other segments of financial services, like money management. The trusted money managers can follow opaque, high-expertise active managerment strategies, whereas those lacking such trust can follow transparent, passive management strategies. When the trusted managers lose trust, that segment of the market will flee to the passive managers. An example of this is the post-crisis "flight" from active money managers to indexed ETFs and mutual funds. ${ }^{38}$

\subsection{Application to Financial Innovation}

Our analysis of trust also provides a perspective on the future evolution of fintech innovations such as "robo advisors" and cryptocurrency like bitcoin. Many of these technologies are quite opaque to investors, especially households. Thus, accoding to our analysis, their acceptance by consumers and their long-run viability depend on the extent to which these technologies are trusted. In this case, trust pertrains not so much to risk-shifting behavior by the platform operator, but to the security of the technology. Events such as hackers stealing large amounts of cryptocurrency erode trust. A strong implication of our analyssis is that trust is a 0-1 phenomenon, so if investors lose trust in these innovations, there will not be a gradual Bayesian belief revision. Rather, there will be a massive flight away from these new technologies. In other words, as long as investors trust these technologies, periodic episodes of breaches and failures will have no apparent effect on the popularity of fintech. But if trust is lost, there will be a sharp drop-off in the acceptance of these technologies.

\section{Conclusion}

This paper has developed a theory of trust in lending. Trust enables lenders to have access to financing at rates that are insulated from the adverse reputational consquences of prior

\footnotetext{
${ }^{38} \mathrm{As}$ an illustration, Vanguard took in about $\$ 280$ billion in net new money in 2016 , greatly surpassing other types of funds, while actively managed funds have experienced consistently large net outflows since 2007. See the Investment Company Institute 2017 Factbook: http://www.icifactbook.org/ch2/17_fb_ch2.
} 
loan defaults as well as market conditions. However, trust can be broken. It is most likely to be eroded when the lender experiences relatively high borrower defaults during an economic boom. Trust is asymmetric - it is easier to lose it than to gain it. The importance of trust varies across banks and fintech lenders. While banks may be able to operate without trust, investor trust is essential for fintech lenders to be able to operate.

From a functional perspective, banks and fintech platforms perform similar lending functions. Our analysis of trust and a characterization of the difference between banks and fintech lenders relies on an essential institutional difference between these lenders-banks have access to insured deposits and they provide valuable depository services to their customers, whereas fintech platforms are entirely investor-financed. This distinction makes banks innactely more trustworthy than fintech platforms, and provides them with a competitive advantage over non-depository lenders on the trust dimension. 


\section{References}

[1] Buchak, Greg, Gregor Matvos, Tomasz Piskorski, and Amit Seru. FinTech, regulatory arbitrage, and the rise of shadow banks. No. w23288. National Bureau of Economic Research, 2017.

[2] Copeland, Adam, Antoine Martin, and Michael Walker. "Repo Runs: Evidence from the Tri-Party Repo Market." The Journal of Finance 69, no. 6 (2014): 2343-2380.

[3] Coval, Joshua, Jakub Jurek, and Erik Stafford. "The economics of structured finance." The Journal of Economic Perspectives 23, no. 1 (2009): 3-25.

[4] de Roure, Calebe, Loriana Pelizzon, and Anjan Thakor, "P2P Lenders versus Banks: Cream Skimming or Bottom Fishing?" Working paper, Goethe University, December, 2017.

[5] Demyanyk, Yuliya S., Elena Loutskina, and Daniel Kolliner. "The Taste of Peer-to-Peer Loans." (2017).

[6] Donaldson, Jason Roderick, Giorgia Piacentino, and Anjan V. Thakor. "Warehouse banking." Forthcoming, Journal of Financial Economics.

[7] Fehr, Ernst. "On the economics and biology of trust." Journal of the european economic association 7, no. 2-3 (2009): 235-266.

[8] Fenwick, Mark, Joseph A. McCahery, and Erik PM Vermeulen. "Fintech and the Financing of Entrepreneurs: From Crowdfunding to Marketplace Lending." (2017).

[9] Foote, Christopher L., Kristopher S. Gerardi, and Paul S. Willen. Why did so many people make so many ex post bad decisions? The causes of the foreclosure crisis. No. w18082. National Bureau of Economic Research, 2012.

[10] Gennaioli, Nicola, Andrei Shleifer, and Robert Vishny. "Neglected risks, financial innovation, and financial fragility." Journal of Financial Economics 104, no. 3 (2012): 452-468.

[11] Gennaioli, Nicola, Andrei Shleifer, and Robert Vishny. "Money doctors." The Journal of Finance 70, no. 1 (2015): 91-114.

[12] Gennaioli, Nicola, Andrei Shleifer, and Robert Vishny. "Neglected risks: The psychology of financial crises." The American Economic Review 105, no. 5 (2015): 310-314.

[13] Gorton, Gary, and Andrew Metrick. "Securitized banking and the run on repo." Journal of Financial Economics 104, no. 3 (2012): 425-451.

[14] Green, Harriet, "Here's Why Banks Have - and Can Keep - the Upper Hand Over P2P Lenders", City A.M. Newsletters, Thursday, May 26, 2016. 
[15] Greenwood, Robin, and David Scharfstein. "The growth of finance." The Journal of Economic Perspectives 27, no. 2 (2013): 3-28.

[16] Guiso, Luigi, Paola Sapienza, and Luigi Zingales. "Trusting the stock market." The Journal of Finance 63, no. 6 (2008): 2557-2600.

[17] Gurun, Umit G., Noah Stoffman, and Scott E. Yonker. "Trust busting: The effect of fraud on investor behavior." forthcoming, The Review of Financial Studies.

[18] Hartman-Glaser, Barney. "Reputation and signaling in asset sales." Journal of Financial Economics 125, no. 2 (2017): 245-265.

[19] He, Dong, Ross Leckow, Vikram Haksar, Tommaso Mancini-Griffoli, Nigel Jenkinson, Mikari Kashima, Tanai Khiaonarong, Celine Rochon, and Hervé Tourpe. "Fintech and Financial Services: Initial Considerations." IMF Staff Discussion Note: Fintech and Financial Services: Initial Considerations 17, no. 05 (2017).

[20] Holmstrom, Bengt, and Joan Ricart I. Costa. "Managerial incentives and capital management." The Quarterly Journal of Economics 101, no. 4 (1986): 835-860.

[21] Iyer, Rajkamal, José-Luis Peydró, Samuel da-Rocha-Lopes, and Antoinette Schoar. "Interbank liquidity crunch and the firm credit crunch: Evidence from the 2007-2009 crisis." The Review of Financial Studies 27, no. 1 (2013): 347-372.

[22] Jagtiani, Julapa, and Catharine Lemieux. "Fintech Lending: Financial Inclusion, Risk Pricing, and Alternative Information." (2017).

[23] Merton, Robert C. "An analytic derivation of the cost of deposit insurance and loan guarantees an application of modern option pricing theory." Journal of Banking \& Finance 1, no. 1 (1977): 3-11.

[24] Merton, Robert C. "On the Cost of Deposit Insurance When There Are Surveillance Costs." The Journal of Business 51, no. 3 (1978): 439-452.

[25] Merton, Robert C. "The financial system and economic performance." In International Competitiveness in Financial Services, pp. 5-42. Springer Netherlands, 1990.

[26] Merton, Robert C., "Operation and Regulation in Financial Intermediation: A Functional Perspective", in Operation and Regulation of Financial Markets, ed. Peter Englund, (The Economic Council, Stockholm, 1993), 17-67.

[27] Merton, Robert C. "A Functional Perspective of Financial Intermediation." Financial Management 24, no. 2 (1995): 23-41.

[28] Merton, Robert C. "A Model of Contract Guarantees for Credit-Sensitive, Opaque Financial Intermediaries." European Finance Review 1, no. 1 (1997): 1-13.

[29] Merton, Robert C., and Zvi Bodie. "A Conceptual Framework for Analyzing the Financial Environment." Chap. 1 in The Global Financial System: A Functional Perspective, by D. B. Crane et. al., 3-31. Boston: Harvard Business School Press, 1995. 
[30] Merton, Robert C., and Zvi Bodie. "Design of Financial Systems: Towards a Syntheses of Function and Structure." Journal of Investment Management 3, no. 1 (2005): 6.

[31] Merton, Robert C., and Richard T. Thakor. "Customers and investors: a framework for understanding the evolution of financial institutions." Forthcoming, Journal of Financial Intermediation.

[32] Morrison, Alan D., and Lucy White. "Crises and capital requirements in banking." American Economic Review 95, no. 5 (2005): 1548-1572.

[33] Morrison, Alan D., and Lucy White. "Reputational contagion and optimal regulatory forbearance." Journal of Financial Economics 110, no. 3 (2013): 642-658.

[34] Ortoleva, Pietro. "Modeling the change of paradigm: Non-Bayesian reactions to unexpected news." The American Economic Review 102, no. 6 (2012): 2410-2436.

[35] Philippon, Thomas. "Has the US finance industry become less efficient? On the theory and measurement of financial intermediation." The American Economic Review 105, no. 4 (2015): 1408-1438.

[36] Philippon, Thomas. The fintech opportunity. No. w22476. National Bureau of Economic Research, 2016.

[37] Salisbury, Ian, "Lending Club's CEO has Left and its Stock has Plunged. Should Lenders Bail Out?", Money, June 13, 2016.

[38] Sanches, Daniel. "Shadow Banking and the Crisis of 2007-08." Federal Reserve Bank of Philadelphia Business Review Q2 (2014): 7-14.

[39] Sapienza, Paola, and Luigi Zingales, "Trust and Finance". NBER Reporter 2011, no. 2: Research Summary, 2011.

[40] Sorkin, Andrew R. "Fintech Firms Are Taking On the Big Banks, but Can They Win?" The New York Times, April 6, 2016.

[41] Wallace, Tim. "Lending Club's Woes Raise Questions for Britain's Peer-to-Peer Lenders", The Telegraph, May 11, 2016.

[42] Weinstein, Jonathan. "Provisional Probabilities and Paradigm Shifts." Unpublished working paper, 2011.

[43] Winton, Andrew, and Vijay Yerramilli. "Lender moral hazard and reputation in originate-to-distribute markets." (2015).

[44] Zetzsche, Dirk A., Ross P. Buckley, Douglas W. Arner, and Janos Nathan Barberis. "From Fintech to Techfin the Regulatory Challenges of Data-Driven Finance." (2017). 


\section{Appendix}

\section{A. Parametric Restrictions}

We present below the formal restrictions on the parameters of the model. We first need some notation as a prelude to the restrictions. Let the lowest possible shares of ownership the bank and the fintech lender must sell to raise the necessary external financing be (respectively):

$$
\begin{gathered}
s_{b}^{*}=\frac{[L-D][1+r]}{\bar{q} \lambda_{b}} \quad(\text { bank }) \\
s_{f}^{*}=\frac{L[1+r]}{\bar{q} \lambda_{f}} \quad \text { (fintech lender) }
\end{gathered}
$$

and define the incremental expected utilities from investing in the $G$ loan relative to the PB loan at the first-best financing costs as:

$$
\begin{array}{ll}
u_{b}^{*}=\alpha[\bar{q}-\bar{p}] \lambda_{b}\left[1-s_{b}^{*}\right] & \text { (bank) } \\
u_{f}^{*}=\alpha[\bar{q}-\bar{p}] \lambda_{f}\left[1-s_{f}^{*}\right] & \text { (bank) }
\end{array}
$$

Also define the incremental expected utility of bank insiders from investing in the $G$ loan at the second-best financing cost as:

$$
\bar{u}_{b}=\alpha[\bar{q}-\bar{p}] \lambda_{b}\left[1-s_{b}^{*}\left[\nu \gamma_{1}\right]^{-1}\right]
$$

and let the bank's adjusted expected utility differential be defined as:

$$
D \equiv u_{b}^{*}-\bar{u}_{b}
$$

We can now state our restrictions on the parameters:

\section{Restriction 1:}

$$
[1-\alpha] \beta_{h}^{1}<u_{b}^{*}<[1-\alpha] \beta_{h}^{2}<u_{b}^{*}+D
$$




\section{Restriction 2:}

$$
[1-\alpha] \beta_{l}^{1}<u_{f}^{*}<[1-\alpha] \beta_{l}^{2}<[1-\alpha] \beta_{l}^{1}<2 u_{f}^{*}<[1-\alpha] \beta_{h}^{2}
$$

Restriction 3:

$$
\bar{u}_{b}>[1-\alpha] \beta_{h}^{1}
$$

Restriction 4:

$\gamma_{1}$ and $C(m, q)$ are intermediate in value $\forall m$

\section{B. Proofs}

Proof of Lemma 1: Since $\hat{\varphi}^{\prime}>r$, it follows that

$$
\int_{0}^{D} \hat{\varphi}^{\prime}(y) d y>\int_{0}^{D} r d y
$$

which means that $\hat{\varphi}(D)>r D$. The depositors' participation constraint (with riskless deposits) is:

$$
D\left[1+r_{D}\right]+\bar{q} \bar{\varphi}(D)+[1-\bar{q}] \hat{\varphi}(D) \geq D[1+r]
$$

Since the zero-lower-bound assumption implies that $r_{D} \geq 0$, if (A.12) holds for $r_{D}=0$, then the competitive equilibrium solution must be $r_{D}=0$ because maximizing the lender's utility implies minimizing the left-hand side of (A.12) while satisfying (A.12). At $r_{D}=0$, (A.12) becomes:

$$
\bar{q} \bar{\varphi}(D)+[1-\bar{q}] \hat{\varphi}(D) \geq r D
$$

Now, $\bar{q} \bar{\varphi}(D)+[1-\bar{q}] \hat{\varphi}(D)>\hat{\varphi}(D)>r D$ by (A.11). Thus, (A.13) holds with $r_{D}=0$.

Proof of Lemma 2: If deposits are riskless, the value of the bank's depository services to its customers is

$$
\bar{q} \bar{\varphi}(D)+[1-\bar{q}] \hat{\varphi}(D)
$$


where we recognize that when the borrower defaults and deposit insurance kicks in, depositors value the bank's services only at $\hat{\varphi}(D)$ even though their financial claim is fully covered. If the bank is unable to fully pay off depositors when the borrower defaults, the value of the bank's depository services to its customers is:

$$
\bar{q} \bar{\varphi}(D)
$$

Thus, the welfare gain due to making deposits riskless is:

$$
[1-\bar{q}] \hat{\varphi}(D)
$$

Now by providing deposit insurance, relative to not providing it, the deposit insurer increases the expected payoff to depositors by

$$
[1-\bar{q}][\hat{\varphi}(D)+D]
$$

The expected cost of providing deposit insurance is

$$
[1-\bar{q}] D[1+r]
$$

Thus, the net welfare benefit of complete deposit insurance provision is the difference between (A.17) and (A.18):

$$
\triangle \equiv[1-\bar{q}][\hat{\varphi}(D)-r D]
$$

From the proof of Lemma 1, we know that $\hat{\varphi}(D)>r D$, which means

$$
\triangle>0
$$

This completes the proof.

Proof of Lemma 3: When there is only one lender, it can act as a monopolist with respect to the borrower, so the repayment obligation is set at the maximum pledgeable cash flow, $x$. When there are two or more lenders, the repayment obligation must be set to yield the lender an expected 
return of $r$ on the loan, which is the minimum return the lender will accept, given its ability to invest its funds at $r$. Thus, $R_{2}^{F B}$ solves:

$$
\bar{q} R_{2}^{F B}=L[1+r]
$$

which yields (13).

Proof of Lemma 4: The result that $R_{1}^{t} \equiv R_{1}=R_{1}^{F B}=x \forall t \in\{0,1\}$ and $R_{2}^{t} \equiv R_{2}=R_{2}^{F B}=$ $\{L[1+r]\}\{\bar{q}\}^{-1} \forall t \in\{0,1\}$ follows from the fact that the lender's loan pricing depends only on whether lenders are competing and the lender's participation constraint (minimum return of $r$ ) and not on the beliefs of investors about the lender's type.

Now $s_{b}^{t}(\omega)$ will be determined to satisfy the outside shareholders' participation constraint, which holds tightly in equilibrium:

$$
\begin{array}{r}
s_{b}^{t}(\omega)\left\{\bar{q} I_{\left\{\pi_{T}\right\}}^{t}+\left[1-I_{\left\{\pi_{T}\right\}}^{t}\right] \sum_{j=1}^{3} \bar{q} \mu_{\omega}^{b}(j) I_{b}^{t}(j)\right\} \lambda_{b} \\
=[L-D][1+r]
\end{array}
$$

where the bank's strategy is restricted to lending (since financing is needed only if the bank decides to make a loan). Solving (A.22) yields (22). Similarly, for the fintech lender, $s_{f}^{t}(\omega)$ solves:

$$
\begin{array}{r}
s_{f}^{t}(\omega)\left\{\bar{q} I_{\left\{\pi_{T}\right\}}^{t}+\left[1-I_{\left\{\pi_{T}\right\}}^{t}\right] \sum_{j=1}^{3} \bar{q} \mu_{\omega}^{f}(j) I_{f}^{t}(j)\right\} \lambda_{f} \\
=L[1+r]
\end{array}
$$

Solving (A.23) yields (23).

Proof of Theorem 1: By the HTR, since $\zeta^{0}>0.5$, the agents' prior over priors will select $\pi^{0}=\pi_{T}$ and lenders will be viewed as trustworthy in the first period. Since $1-C(\bar{m}, q)<\varepsilon$, it follows that if the lender experiences default and $\tilde{m}=\bar{m}$, then by the HTR agents will reject their initial prior $\pi_{T}$ and go back to their prior over priors to update using Bayes' rule. They will 
compute the posterior belief

$$
\zeta^{1}=\frac{[1-C(\bar{m}, q)] \zeta^{0}}{[1-C(\bar{m}, q)] \zeta^{0}+q_{F}(\bar{m})\left[1-\zeta^{0}\right]}
$$

where $q_{F}(\bar{m})$ is the expected failure probability in macro state $\bar{m}$ if the lender is self-interested, given the optimal strategies untrustworthy lenders would have chosen in the first period (with the expectation taken over lender types in Model II) when faced with agents believing them to be trustworthy.

Note that $\zeta^{1}$ is decreasing in $q_{F}(\bar{m})$. The higher the probability that a type- $\tau_{j}(j \in\{1,2\})$ lender makes the $G$ loan in the first period, the lower is $q_{F}(\bar{m})$ and hence the higher is $\zeta^{1}$. The maximum probability that a type- $\tau_{j}$ lender will make the $G$ loan is 1 . Thus, if we can establish that $\zeta^{1}<0.5$ with this conjectured first-period strategy chosen by type $\tau_{j}$, then $\zeta^{1}<0.5$ with any first-period strategy chosen by the type- $\tau_{j}$ lender.

Now if the type- $\tau_{j}$ makes the $G$ loan with probability 1 in the first period $\forall j \in\{1,2\}$, then

$$
q_{F}(\bar{m})=1-C(\bar{m}, q) \sum_{j=1}^{2} \mu_{\bar{m}}(j)
$$

where $\mu_{\bar{m}}(j)$ is defined in (25), with the superscript $i$ dropped, $\omega=\bar{m}$, and recognizing that the posterior is after observing default at $t=1$, it can be written as:

$$
\mu_{\bar{m}}(j)=\frac{[1-C(\bar{m}, q)] \gamma_{j}}{[1-C(\bar{m}, q)] \sum_{j=1}^{2} \gamma_{j}+1-\gamma_{1}-\gamma_{2}}
$$

with $j \in\{1,2\}$. Substituting this in (A.25), the condition for $\zeta^{1}<0.5$ becomes:

$$
\frac{[1-C(\bar{m}, q)] \zeta^{0}}{[1-C(\bar{m}, q)] \zeta^{0}+[1-\mu \bar{m}(j) C(\bar{m}, q)]\left[1-\zeta^{0}\right]}<0.5
$$

where

$$
\bar{\mu}_{\bar{m}} \equiv \sum_{j=1}^{2} \mu_{\bar{m}}(j)
$$


Simplifying this yields

$$
\zeta^{0}<\frac{1-C(\bar{m}, q) \bar{\mu}_{\bar{m}}}{2-C(\bar{m}, q)\left[1+\bar{\mu}_{\bar{m}}\right]}
$$

Note that since $\bar{\mu}_{\bar{m}}<1$, the quantity on the right-hand side of (A.29) is bigger than 0.5. Thus, the interval defined in (24) has positive Lebesgue measure.

So we have proven that at $\tilde{m}=\bar{m}$, if the lender experiences borrower default, by HTR the prior over priors will reject the intially chosen Model I as the correct belief and the revised prior over priors at $t=1$ will choose Model II as the correct prior for the second period. This holds for any first-period strategy chosen by the lender. By continuity, $\exists m^{*}$ in the neighborhood of $\bar{m}$ for which this will be true as well. Further, given $\varepsilon<1-C(\underline{m}, q)$ in $(26)$, it also follows that the initial prior is not rejected if $\tilde{m}=\underline{m}$. Thus, $m^{*} \in(\underline{m}, \bar{m})$.

It is straightforward that the initial prior will not be rejected for any $\tilde{m}$ if the lender experiences success (borrower-repayment) at $t=1$.

Proof of Corollary 1: At $t=0$, agents believe that all lenders are trustworthy. Thus, all make $G$ loans and the probability of failure for every lender is $1-C(m, q)$ in every $m \in[\underline{m}, \bar{m}]$. By Theorem 1 , if $m>m^{*}$, then the HTR will reject the initial hypothesis that the lender is trustworthy if default is experienced, and if $m \leq m^{*}$, the HTR will not reject the initial hypothesis. Moreover, since every trustworthy lender had the same strategy in the first period, $\zeta^{1}$ (see (A.24)) is also the same for every lender. The result now follows from Theorem 1.

Proof of Theorem 2: Part (i) of the theorem is clear, given that the type- $\tau_{0}$ lenders always choose $G$. To prove part (ii), note that the expected utility of the insider of a type- $\tau_{i}(i \in\{1,2\})$ bank from making the $G$ loan is

$$
\alpha\left[1-s_{b}^{t}\right] \lambda_{b} \bar{q}
$$

where $\omega$, the argument of $s_{b}^{t}$, is suppressed. The expected utility from a PB loan is

$$
\alpha\left[1-s_{b}^{t}\right] \lambda_{b} \bar{p}+[1-\alpha] \beta_{j}^{i}
$$


where $j \in\{l, h\}$ and $i \in\{1,2\}$. Thus, the incentive compatibility (IC) constraint for the bank to prefer the $G$ loan to the $\mathrm{PB}$ loan is:

$$
\alpha \lambda_{b}\left[1-s_{b}^{t}\right][\bar{q}-\bar{p}]>[1-\alpha] \beta_{j}^{i}
$$

The analogous IC constraint for the fintech lender is:

$$
\alpha \lambda_{f}\left[1-s_{f}^{t}\right][\bar{q}-\bar{p}]>[1-\alpha] \beta_{j}^{i}
$$

Thus, to show that the bank has a stronger incentive to make the $G$ loan than a comparable fintech lender, we need to show that:

$$
\left[1-s_{b}^{t}\right][\bar{q}-\bar{p}] \lambda_{b}>\left[1-s_{f}^{t}\right][\bar{q}-\bar{p}] \lambda_{f}
$$

For this comparison, we need to have the same posterior belief about the lender's type for both the bank and the fintech lender. That is, let

$$
\begin{aligned}
\xi & \equiv \bar{q} I_{\left\{\pi_{T}\right\}}^{t}+\left[1-I_{\left\{\pi_{T}\right\}}^{t}\right] \sum_{j=1}^{3} \bar{q} \mu_{\omega}^{b}(j) I_{b}^{t}(j) \\
& =\bar{q} I_{\left\{\pi_{T}\right\}}^{t}+\left[1-I_{\left\{\pi_{T}\right\}}^{t}\right] \sum_{j=1}^{3} \bar{q} \mu_{\omega}^{f}(j) I_{b}^{t}(j)
\end{aligned}
$$

Then using (22) and (23) we can write:

$$
\begin{gathered}
s_{b}^{t}=\frac{L[1+r]-D[1+r]}{\lambda_{b} \xi} \\
s_{f}^{t}=\frac{L[1+r]}{\lambda_{f} \xi}
\end{gathered}
$$

with (using (20) and (21)):

$$
\lambda_{b}=\lambda_{f}-D
$$


(A.35) thus requires showing that:

$$
\left[1-s_{b}^{t}\right] \lambda_{b}>\left[1-s_{f}^{t}\right] \lambda_{f}
$$

Substituting in (A.39) from (A.36) and (A.37):

$$
\frac{\left\{\xi \lambda_{b}-L[1+r]+D[1+r]\right\}}{\lambda_{b} \xi} \lambda_{b}>\frac{\left\{\xi \lambda_{f}-L[1+r]\right\}}{\lambda_{f} \xi} \lambda_{f}
$$

or, re-writing this:

$$
\xi \lambda_{b}-L[1+r]+D[1+r]>\xi \lambda_{f}-L[1+r]
$$

And substituting in (A.41) from (A.38) we have:

$$
\xi\left[\lambda_{f}-D\right]+D[1+r]>\xi \lambda_{f}
$$

which requires:

$$
D\{1+r-\xi\}>0
$$

which is true since $\xi$ is a probability.

Proof of Lemma 5: Given Theorem 2, we know that, conditional on identical investor beliefs about their types, banks have stronger incentives to make $G$ loans than fintech lenders. Here lenders are trusted in the second period, so $\xi=\bar{q}$ for both banks and fintech lenders. The strategies of the type- $\tau_{0}$ bank and fintech lender stated in the lemma are clear. The same is true for the type- $\tau_{3}$ bank and fintech lender.

For the type- $\tau_{1}$ bank the IC constraint associated with the conjectured strategy is (using (A.33)):

$$
\alpha \lambda_{b}\left[1-s_{b}^{t}\right][\bar{q}-\bar{p}]>[1-\alpha] \beta_{h}^{1}
$$

whereas for the type- $\tau_{2}$ we need:

$$
\alpha \lambda_{b}\left[1-s_{b}^{t}\right][\bar{q}-\bar{p}]>[1-\alpha] \beta_{l}^{2}
$$


and

$$
\alpha \lambda_{b}\left[1-s_{b}^{t}\right][\bar{q}-\bar{p}]<[1-\alpha] \beta_{h}^{2}
$$

Since $\beta_{l}^{2}<\beta_{h}^{1}<\beta_{h}^{2}$, and (A.7) holds, it is possible for (A.44), (A.45), and (A.46) hold simultaneously.

In the case of the fintech lender, for the conjectured strategies to hold, we need:

$$
\begin{gathered}
\alpha \lambda_{f}\left[1-s_{f}^{t}\right][\bar{q}-\bar{p}]>[1-\alpha] \beta_{l}^{1} \\
\alpha \lambda_{f}\left[1-s_{f}^{t}\right][\bar{q}-\bar{p}]<[1-\alpha] \beta_{h}^{1}
\end{gathered}
$$

and

$$
\alpha \lambda_{f}\left[1-s_{f}^{t}\right][\bar{q}-\bar{p}]<[1-\alpha] \beta_{l}^{2}
$$

Given (A.8), we know that (A.47), (A.48), and (A.49) hold at the same time. Thus, the optimal second-period strategies of lenders are as described in the lemma.

Proof of Lemma 6: Consider banks first. We will show that the strategies characterized in the lemma constitute a (subgame perfect) Nash equilibrium. Without trust, given the conjectured strategies of banks stated in the lemma, investors set:

$$
\xi=\mu_{\omega}^{b}(1) \nu \bar{q}
$$

Note that types $\tau_{0}$ and $\tau_{3}$ will obviously follow the lending strategies stipulated in the lemma, so we can focus on types $\tau_{1}$ and $\tau_{2}$. For the type- $\tau_{1}$ bank to find this lending strategy optimal, the IC constraints below must be satisfied:

$$
\begin{gathered}
\alpha \lambda_{b}\left[1-s_{b}^{1}\right][\bar{q}-\bar{p}]>[1-\alpha] \beta_{l}^{1} \\
\alpha \lambda_{b}\left[1-s_{b}^{1}\right][\bar{q}-\bar{p}]<[1-\alpha] \beta_{h}^{1}
\end{gathered}
$$


where $\lambda_{b}$ is given by (20) and

$$
s_{b}^{1}=\frac{L[1+r]-D[1+r]}{\lambda_{b}\left\{\mu_{\omega}^{b}(1) \nu \bar{q}\right\}}
$$

For the type- $\tau_{2}$ bank, the analogous IC constraint is:

$$
\alpha \lambda_{b}\left[1-s_{b}^{1}\right][\bar{q}-\bar{p}] \leq[1-\alpha] \beta_{l}^{2}
$$

Since $\beta_{l}^{1}<\beta_{l}^{2}$ and $\beta_{l}^{1}<\beta_{h}^{1}$, note that if (A.54) holds, so will (A.52). Given the parametric restrictions in Appendix A, (A.51), (A.52), and (A.54) hold simultaneously. Hence, the bank's strategies and investors' beliefs constitute a Nash equilibrium.

Now consider the fintech lender's strategy. Suppose counterfactually that investors believe that a fintech lender of type $\tau_{i}(i \in\{1,2\})$ will follow the same lending strategy as a bank of that type. We know by Theorem 2 that a fintech lender has a weaker incentive to make a $G$ loan than a bank of the same type, given the same investor beliefs, so the fintech lender can never be believed to invest in $G$ with a higher probability than a bank (for the same $\omega$ realization). Then the relevant IC constraint for the fintech lender correpsonding to the strategy stipulated in the lemma is:

$$
\alpha \lambda_{f}\left[1-s_{f}^{1}\right][\bar{q}-\bar{p}] \leq[1-\alpha] \beta_{l}^{1}
$$

where $\lambda_{f}$ is given by $(21)$ and

$$
s_{f}^{1}=\frac{L[1+r]}{\lambda_{f}\left\{\mu_{\omega}^{b}(1) \nu \bar{q}\right\}}
$$

if we assume (counterfactually) that investors have the same beliefs about the fintech lender's types and strategies as they do about the bank.

Now solve for the value of $\mu_{\omega}^{b}(1)$, call it $\hat{\mu}_{\omega}^{b}(1)$, such that (A.55) holds as an equality. If we choose $\mu_{\omega}^{b}(1)=\hat{\mu}_{\omega}^{b}(1)-\bar{\varepsilon}$, where $\bar{\varepsilon}>0$ is arbitrarily small, then (A.55) will hold and (A.51) will hold since $\lambda_{b}>\lambda_{f}$. Next, find the value of $\mu_{\omega}^{b}(1)$, call it $\widetilde{\mu}_{\omega}^{b}(1)$, such that (A.54) holds as an equality. Choose $\mu_{\omega}^{b}(1)=\min \left\{\hat{\mu}_{\omega}^{b}(1), \widetilde{\mu}_{\omega}^{b}(1)\right\}-\bar{\varepsilon}$. Then (A.54) will hold, and (A.51) and (A.55) will continue to hold.

Thus, investors will believe that a type $\tau_{i}(i \in\{1,2,3\}$ fintech lender will not invest in loan $G$ with a positive probability. Given the absence of trust, the fintech lender will therefore be unable 
to raise financing. Finally, note that since (A.51) holds, $s_{b}^{1}<1$, which means $\mu_{\omega}^{b}(1)$ cannot be too small, i.e., it takes an intermediate value. Restriction 4 ensures that $\mu_{\omega}^{b}(1)$ is intermediate in value.

Proof of Theorem 3: We will focus on the strategies of types $\tau_{1}, \tau_{2}$, and $\tau_{3}$. Let $u_{i j}^{2}$ be the second-period utility of lender $i \in\{b, f\}$ of type $j \in\{1,2,3\}$ (where 1 represents $\tau_{1}, 2$ represents $\tau_{2}$, and 3 represents $\tau_{3}$ ), when the lender is trusted in the second period and $\hat{u}_{i j}^{2}$ be the corresponding utility when the lender is not trusted. The theorem assumes the condition that all lenders are trusted in the first period. We will now validate that the strategies stipulated in the theorem represent a Nash equilibrium, given investors' beliefs.

Consider banks first. Since type- $\tau_{1}$ banks have a stronger incentive than type- $\tau_{2}$ banks to make $G$ loans, and since a bank has a stronger incentive than a fintech lender to make a $G$ loan, to validate the strategies of the banks of types $\tau_{1}$ and $\tau_{2}$, and the fintech lender of type $\tau_{1}$, it suffices to check that the following IC constraints are satisfied. The first is that the type- $\tau_{2}$ bank prefers $G$ to $P B \forall \beta$ :

$$
\begin{array}{r}
\alpha\left\{\left[1-s_{b}^{0}\right] \bar{q} \lambda_{b}+\left\{\bar{q}+[1-\bar{q}] \int_{\underline{m}}^{m^{*}} \eta d m\right\} u_{b 2}^{2}+[1-\bar{q}]\left[\int_{m^{*}}^{\bar{m}} \eta d m\right] \hat{u}_{b 2}^{2}\right\} \\
\geq \alpha\left\{\left[1-s_{b}^{0}\right] \bar{p} \lambda_{b}+\left\{\bar{p}+[1-\bar{p}] \int_{\underline{m}}^{m^{*}} \eta d m\right\} u_{b 2}^{2}+[1-\bar{p}]\left[\int_{m^{*}}^{\bar{m}} \eta d m\right] \hat{u}_{b 2}^{2}\right\}+[1-\alpha] \beta_{h}^{2}
\end{array}
$$

The second is that the type- $\tau_{1}$ fintech lender prefers $G$ to $\mathrm{PB} \forall \beta$ :

$$
\begin{array}{r}
\alpha\left\{\left[1-s_{f}^{0}\right] \bar{q} \lambda_{f}+\left\{\bar{q}+[1-\bar{q}] \int_{\underline{m}}^{m^{*}} \eta d m\right\} u_{f 1}^{2}+[1-\bar{q}]\left[\int_{m^{*}}^{\bar{m}} \eta d m\right] \hat{u}_{f 1}^{2}\right\} \\
\geq \alpha\left\{\left[1-s_{f}^{0}\right] \bar{p} \lambda_{f}+\left\{\bar{p}+[1-\bar{p}] \int_{\underline{m}}^{m^{*}} \eta d m\right\} u_{f 1}^{2}+[1-\bar{p}]\left[\int_{m^{*}}^{\bar{m}} \eta d m\right] \hat{u}_{f 1}^{2}\right\}+[1-\alpha] \beta_{h}^{1}
\end{array}
$$

The third is that the type- $\tau_{2}$ fintech lender prefers $G$ to $\mathrm{PB}$ for $\beta=\beta_{l}^{2}$ :

$$
\begin{array}{r}
\alpha\left\{\left[1-s_{f}^{0}\right] \bar{q} \lambda_{f}+\left\{\bar{q}+[1-\bar{q}] \int_{\underline{m}}^{m^{*}} \eta d m\right\} u_{f 2}^{2}+[1-\bar{q}]\left[\int_{m^{*}}^{\bar{m}} \eta d m\right] \hat{u}_{f 2}^{2}\right\} \\
\geq \alpha\left\{\left[1-s_{f}^{0}\right] \bar{p} \lambda_{f}+\left\{\bar{p}+[1-\bar{p}] \int_{\underline{m}}^{m^{*}} \eta d m\right\} u_{f 2}^{2}+[1-\bar{p}]\left[\int_{m^{*}}^{\bar{m}} \eta d m\right] \hat{u}_{f 2}^{2}\right\}+[1-\alpha] \beta_{l}^{2}
\end{array}
$$


And the fourth is that the type- $\tau_{2}$ fintech lender prefers PB to $G$ for $\beta=\beta_{h}^{2}$ :

$$
\begin{array}{r}
\alpha\left\{\left[1-s_{f}^{0}\right] \bar{q} \lambda_{f}+\left\{\bar{q}+[1-\bar{q}] \int_{\underline{m}}^{m^{*}} \eta d m\right\} u_{f 2}^{2}+[1-\bar{q}]\left[\int_{m^{*}}^{\underline{m}} \eta d m\right] \hat{u}_{f 2}^{2}\right\} \\
<\alpha\left\{\left[1-s_{f}^{0}\right] \bar{p} \lambda_{f}+\left\{\bar{p}+[1-\bar{p}] \int_{\underline{m}}^{m^{*}} \eta d m\right\} u_{f 2}^{2}+[1-\bar{p}]\left[\int_{m^{*}}^{\bar{m}} \eta d m\right] \hat{u}_{f 2}^{2}\right\}+[1-\alpha] \beta_{h}^{2}
\end{array}
$$

The relevant second-period utilities with and without trust were derived in the proofs of the previous results. From those proofs, we know that

$$
\begin{aligned}
& u_{i j}^{2}>\hat{u}_{i j}^{2} \\
& u_{b j}^{2}>u_{f j}^{2} \\
& \hat{u}_{b j}^{2}>\hat{u}_{f j}^{2}
\end{aligned}
$$

Noting that $\alpha[\bar{q}-\bar{p}] u_{b 2}^{2}=u_{b}^{*}, \alpha[\bar{q}-\bar{p}] u_{f}^{2}=u_{f}^{*}$ for $i \in\{1,2\}$, and $\alpha[\bar{q}-\bar{p}] \hat{u}_{b 2}^{2}=\bar{u}_{b}$, and that a fintech lender lacking trust is locked out of the market in the second period, we can write (A.57), (A.58), and (A.60) respectively as:

$$
\begin{gathered}
u_{b}^{*}+\left[1-\int_{\underline{m}}^{m^{*}} \eta d m\right] u_{b}^{*}+\left[\int_{m^{*}}^{\bar{m}} \eta d m\right] \bar{u}_{b} \geq[1-\alpha] \beta_{h}^{2} \\
u_{f}^{*}+\left[1-\int_{\underline{m}}^{m^{*}} \eta d m\right] u_{f}^{*} \geq[1-\alpha] \beta_{h}^{1} \\
u_{f}^{*}+\left[1-\int_{\underline{m}}^{m^{*}} \eta d m\right] u_{f}^{*} \geq[1-\alpha] \beta_{l}^{2} \\
u_{f}^{*}+\left[1-\int_{\underline{m}}^{m^{*}} \eta d m\right] u_{f}^{*}<[1-\alpha] \beta_{h}^{2}
\end{gathered}
$$

Now, in the limit as $m^{*} \rightarrow \underline{m}$, we see that (A.7) guarantees that (A.64) holds and (A.8) guarantees that (A.65), (A.66), and (A.67) hold. By continuity, therefore, these inequalities will hold for $m^{*}>\underline{m}$, given a small enough measure of $\left[\underline{m}, m^{*}\right]$, i.e., for $\underline{m}$ high enough. The rest of the theorem follows from the previous proofs. 
Proof of Theorem 4: Consider first the strategies of banks, Given the arguments in the proof of Theorem 3, we need to show that it is possible for (A.57) to hold and for the following IC constraints to hold (where the beliefs of investors at $t=0$ are consistent with the conjectured equilibrium strategies of banks) and we utilize the assumption that if a lender does not have trust at $t=0$, it can never gain it at $t=1$ ). The first is that the type- $\tau_{1}$ bank prefers the $G$ loan $\forall \beta$ :

$$
\alpha\left\{\left[1-\hat{s}_{b}^{0}\right] \bar{q} \lambda_{b}+\hat{u}_{b 1}^{2}\right\} \geq \alpha\left\{\left[1-\hat{s}_{b}^{0}\right] \bar{p} \lambda_{b}+\hat{u}_{b 1}^{2}\right\}+[1-\alpha] \beta_{h}^{1}
$$

The second is that the type- $\tau_{2}$ bank prefers the $G$ loan for $\beta=\beta_{l}$ :

$$
\alpha\left\{\left[1-\hat{s}_{b}^{0}\right] \bar{q} \lambda_{b}+\hat{u}_{b 2}^{2}\right\} \geq \alpha\left\{\left[1-\hat{s}_{b}^{0}\right] \bar{p} \lambda_{b}+\hat{u}_{b 2}^{2}\right\}+[1-\alpha] \beta_{l}^{2}
$$

The third is that the type- $\tau_{2}$ bank prefers the PB loan for $\beta=\beta_{h}$ :

$$
\alpha\left\{\left[1-\hat{s}_{b}^{0}\right] \bar{q} \lambda_{b}+\hat{u}_{b 2}^{2}\right\}<\alpha\left\{\left[1-\hat{s}_{b}^{0}\right] \bar{p} \lambda_{b}+\hat{u}_{b 2}^{2}\right\}+[1-\alpha] \beta_{h}^{2}
$$

In the above,

$$
\hat{s}_{b}^{0}=\frac{[L-D][1+r]}{\bar{q}\left[\gamma_{1}+\nu \gamma_{2}\right] \lambda_{b}}
$$

Now, following steps similar to those in the proof of the previous theorem, we can write (A.68)(A.70) as:

$$
\begin{aligned}
& \alpha\left[1-\hat{s}_{b}^{0}\right][\bar{q}-\bar{p}] \lambda_{b} \geq[1-\alpha] \beta_{h}^{1} \\
& \alpha\left[1-\hat{s}_{b}^{0}\right][\bar{q}-\bar{p}] \lambda_{b} \geq[1-\alpha] \beta_{l}^{2} \\
& \alpha\left[1-\hat{s}_{b}^{0}\right][\bar{q}-\bar{p}] \lambda_{b}<[1-\alpha] \beta_{h}^{2}
\end{aligned}
$$

Now note that

$$
\hat{s}_{b}^{0}<s_{b}^{*}\left[\nu \gamma_{1}\right]^{-1}
$$

which means that

$$
\alpha\left[1-\hat{s}_{b}^{0}\right][\bar{q}-\bar{p}] \lambda_{b}>\bar{u}_{b}>[1-\alpha] \beta_{h}^{1}
$$


where (A.76) follows from (A.5). Given this, (A.72) holds. Moreover, (A.73) also holds since $\beta_{l}^{2}<\beta_{h}^{1}$. Finally, since

$$
\alpha\left[1-\hat{s}_{b}^{0}\right][\bar{q}-\bar{p}] \lambda_{b}<u_{b}^{*}
$$

and $u_{b}^{*}<[1-\alpha] \beta_{h}^{2}$ by (A.7), we see that (A.77) guarantees that (A.75) holds. Thus, the strategies in the theorem constitute a Nash equilibrium.

For the fintech lenders, given that it is impossible to gain trust in the second period once it is absent in the first period and the result in lemma 6 that absent trust, a fintech lender is shut out of the market in the second period, the first-period problem is the same as the second-period problem without trust. But we know from Lemma 6 that in this case, no financing is available to the lender.

Proof of Theorem 5: Assume (26) holds. Then we have already established in Corollary 1 that a lender who starts out being trusted can lose trust if default is experienced at $t=1$ at $m>m^{*}$. So what we need to prove is that, for the same set of parameter values, a lender who starts out not being trusted can never gain trust in the future.

So suppose agents start out at $t=0$ with Model II. The only way for lenders to gain trust at $t=1$ is if they experience first-period loan repayment. Suppose this happens when $m=\underline{m}$, so the repayment probability of the $G$ loan is $C(\underline{m}, q)$. Clearly, if trust cannot be regained with loan repayment when $m=\underline{m}$, it cannot be regained with $m>\underline{m}$. The HTR will reject the initially-adopted Model II if

$$
\left[\gamma_{1}+\nu \gamma_{2}\right] C(\underline{m}, q)>\varepsilon
$$

where it is recognized that with Model II only the type- $\tau_{1}$ lenders and type- $\tau_{2}$ lenders with $\tilde{\beta}_{2}=\beta_{2}^{l}$ choose loan $G$, so $\gamma_{1}+\nu \gamma_{2}$ is the probability measure of lenders choosing loan $G$ (Theorem 4). Since $\varepsilon$ is arbitrarily small, (A.78) holds. Thus, trust will never be gained at $t=1$. 